\title{
Brasil: dinámica de la industria de bienes de capital en el ciclo de expansivo 2003-2008 $y$ tras la crisis mundial
}

\author{
Guilherme Riccioppo Magacho
}

RESUMEN

La industria de bienes de capital es esencial para el desarrollo tecnológico y para garantizar un crecimiento económico a largo plazo sin restricciones externas. En el Brasil, después de un largo período de estancamiento, las inversiones volvieron a crecer a partir de 2003, dando nuevo impulso a la industria de bienes de capital. Sin embargo, se trata de una industria bastante heterogénea; mientras que en algunos sectores no se logró cubrir la expansión de la demanda, esto fue posible en otros que evidenciaron un elevado potencial tecnológico, como los proveedores de máquinas para las industrias del petróleo, la minería y la construcción, y los fabricantes de equipos de transporte y de generación y distribución de energía eléctrica. Esos sectores continuaron expandiéndose incluso en el período posterior a la crisis mundial de 2008 y casi no fueron afectados por la competencia internacional.

PALABRAS CLAVE

CLASIFICACIÓN JEL

AUTOR
Industria, bienes de capital, desarrollo industrial, política industrial, Brasil

J60, O14, F14

Guilherme Riccioppo Magacho es Doctor en Economía de la Tierra por la Universidad de Cambridge, Reino Unido de Gran Bretaña e Irlanda del Norte.grm35@cam.ac.uk 


\section{I}

\section{Introducción}

Debido a que comprende la fabricación del conjunto de máquinas necesarias para la producción de otros bienes, la industria de bienes de capital es fundamental para el desarrollo económico. Por una parte, esta industria desempeña un papel relevante en la difusión del progreso técnico - al tiempo que acerca al usuario de la tecnología a su productor- $-y$, en consecuencia, es de vital importancia para el avance tecnológico de una economía (Lundvall, 1988). Por otra, contribuye a reducir la vulnerabilidad externa, pues el crecimiento económico en ausencia de partes relevantes de ese sector supone una mayor dependencia de las exportaciones netas de los demás sectores de la economía, o del ingreso de capitales extranjeros a fin de garantizar las divisas necesarias para el aumento de la inversión ${ }^{1}$.

A partir de esas dos perspectivas, la evaluación del sector productor de bienes de capital cobra gran importancia para estimar la posibilidad de crecimiento económico en los próximos años, ya sea en un contexto externo favorable, como el que se verificó entre 2003 y 2008, o en uno menos adecuado para la expansión productiva, como el que se creó después de la crisis financiera internacional de 2008.

Tras haber sufrido una perturbación en la estructura de la oferta en la década de 1980 (cuando se incorporó

\footnotetext{
$\square$ Este trabajo se basa en la tesis de maestría del autor, defendida en el Instituto de Economía/Universidad Estadual de Campinas (UNICAMP). El autor agradece al Profesor Mariano Laplane, que fue su tutor, y a los profesores Rogério Gomes y Célio Hiratuka por sus aportes en la calificación y la defensa de la tesis. Agradece también las sugerencias y los comentarios realizados por un revisor anónimo de esta revista.

1 Gouvea y Lima (2013) muestran que el sector de máquinas y equipos es uno de los que presentan mayor elasticidad-ingreso de las importaciones y exportaciones. Esto demuestra la importancia del sector para garantizar un crecimiento sostenible a largo plazo, sin restricciones en la balanza de pagos.
}

la microelectrónica a los procesos productivos y los productos) y una nueva sacudida en la década de 1990 (en el marco de la liberalización comercial y las bajas tasas de crecimiento), la industria productora de máquinas y equipos experimentó una tercera perturbación: el ciclo de expansión económica observado a partir de 2003, que parecía señalar la inversión de la tendencia al estancamiento que había durado por lo menos dos décadas, trajo aparejado un considerable aumento de las inversiones y, en consecuencia, de la demanda de bienes de capital.

A objeto de establecer la posible expansión del sector en el caso de que el crecimiento económico sea continuo, se evalúan la diversificación del sector en términos de capacidad de satisfacer la demanda interna y su estructura de producción y competencia. De ese modo, se procura consolidar los datos necesarios sobre la estructura de los diversos segmentos de la industria de bienes de capital, datos que permiten analizar sus repercusiones en el crecimiento económico y el desarrollo tecnológico del país.

El artículo se divide en cinco secciones, incluida esta Introducción. En la segunda sección se realiza una breve descripción del ciclo de expansión reciente y se destacan sus orígenes y consecuencias inmediatas para la economía brasileña y, en particular, sus repercusiones en las inversiones sectoriales. En la tercera sección se presentan la metodología utilizada para evaluar esa industria y la segmentación adoptada. En la cuarta sección se describe brevemente la situación actual de la industria de bienes de capital en términos genéricos y se analizan los principales segmentos de dicha industria, destacando sus diferencias con respecto a las demandas sectoriales. Por último, a modo de conclusión, se presentan los principales aspectos del análisis con miras a la construcción de una política industrial eficaz para el sector de bienes de capital. 


\section{II \\ El ciclo de expansión 2003-2008 y la nueva dinámica del período posterior a la crisis}

En el Brasil, las décadas de 1980 y 1990 se caracterizaron sobre todo por el estancamiento económico. En ese período se registraron bajas tasas de crecimiento asociadas a un alto nivel de desempleo y reducidas inversiones en capital fijo. Si bien hubo algunos ciclos de expansión, como por ejemplo en el período 19951997 (que Bielschowsky (1999) denominó "miniciclo de modernización"), la tendencia general en esas dos décadas -que persistió incluso en los primeros años de la década de 2000 — fue la disminución del nivel de actividad económica, acompañada de un aumento del número de trabajadores desocupados y una reducción de los niveles de inversión global de la economía.

No obstante, ese período de estancamiento cesó en 2004 y la economía brasileña retomó una trayectoria de crecimiento económico sostenido: las tasas medias de expansión pasaron del 2,1\% anual en el cuadrienio 19992002 al 3,5\% anual en el período 2003-2006 y al 4,5\% anual entre 2007 y 2010. Sin embargo, esa expansión perdió impulso después del estallido de la crisis de 2008, y en el trienio 2011-2013 la tasa de crecimiento descendió a los niveles del período 1999-2002 (media del 2,1\% al año) (véase el gráfico 1).

\section{Caracterización general del ciclo de expansión 2003-2008 y del estancamiento posterior a la crisis}

La reanudación del crecimiento y la rápida expansión del comercio internacional, derivados de la recuperación de los niveles de liquidez y de la creciente demanda china, modificaron algunos de los aspectos que hasta entonces caracterizaban a la economía mundial. Los precios en dólares de los productos básicos se recuperaron a partir de 2003, invirtiendo la tendencia decreciente de los últimos años, y los flujos de capitales se orientaron a los países emergentes, que - a raíz de la disminución de los márgenes de las tasas de interés de su deuda soberana y de la inversión de los flujos comerciales- registraron una considerable mejora en la balanza de pagos (Serrano y Summa, 2011).

Ese mejoramiento de las condiciones externas para los países emergentes (en particular, los exportadores netos de productos básicos) contribuyó al cambio de trayectoria de esas economías, que crecieron a tasas más elevadas con respecto a los años anteriores. El caso del Brasil no fue diferente: una vez pasada la crisis que se instalaría con

GRÁFICO 1

Brasil: tasa anual de crecimiento económico, 1990-2013

(Variación anual, en porcentajes)

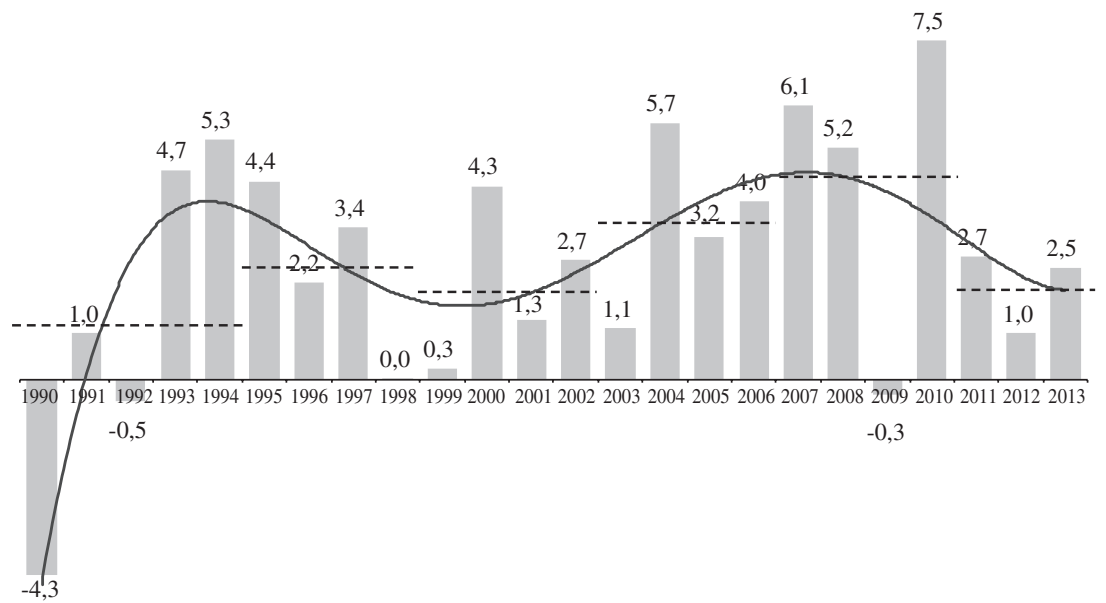

Fuente: Elaboración propia sobre la base del Sistema de Cuentas Nacionales del Instituto Brasileño de Geografía y Estadística (IBGE). 
la transición de gobierno, la economía nacional comenzó a beneficiarse de las condiciones externas.

Como se muestra en el gráfico 2, a partir de 2004 aumenta la utilización de la capacidad instalada, que pasa del $80,3 \%$ al $83,3 \%$ entre 2003 y 2006. Esto se traduce en un incremento de la tasa de inversión, especialmente en el sector de máquinas y equipos, que aumenta del 7,2\% al 8,5\% del producto interno bruto (PIB) en el mismo período. Esa tendencia se acentúa en 2007 y 2008, cuando el nivel de utilización de la capacidad instalada supera el $85 \%$ y la demanda parece sostenible, de manera que la tasa de inversión - cuyo principal componente pasó a ser el consumo de máquinas y equipos- llega al 19,1\%.

Sin embargo, el marcado deterioro de la tasa de utilización a partir de 2010, debido a la incertidumbre con respecto a las demandas externa e interna, condujo a una reducción de la tasa de inversión en máquinas y equipos, que disminuyó del 10,2\% al 9,0\% en 2012, para luego aumentar al 9,5\% en 2013.

Ese nuevo contexto difiere bastante del ciclo de expansión del período 2003-2008. A partir de ese último año, las economías emergentes registraron tasas de crecimiento mucho menores, mientras que las economías desarrolladas presentaron tasas negativas o quedaron prácticamente estancadas ${ }^{2}$. Eso repercutió significativamente en la economía brasileña: a pesar de

2 De acuerdo con el Banco Mundial (Indicadores del Desarrollo Mundial), las economías avanzadas crecieron a un promedio del 2,5\% al año en el período 2003-2008, pero apenas a un 0,8\% anual en el período 2008-2013, mientras que la tasa de crecimiento de los países emergentes disminuyó del 7,4\% al 5,3\% anual en el mismo período. las medidas anticíclicas adoptadas para hacer frente a la crisis, la tasa de crecimiento se redujo y la demanda de productos importados aumentó en virtud de la apreciación de la moneda brasileña en términos reales a partir de 2011 y del exceso de oferta de productos manufacturados, debido a la pérdida de dinamismo de la demanda a nivel mundial.

\section{Efectos del ciclo de expansión en las inversiones sectoriales}

A pesar de evidenciarse en la industria en general, el incremento de la producción en el período 2003-2008 y, específicamente, el aumento de las inversiones, no pueden extenderse a todos los sectores. Algunos grupos de actividades industriales se convirtieron en los principales responsables del aumento de las inversiones empresariales en ese período, ya sea por sus actividades exportadoras (como se vio anteriormente) o porque la penetración de productos importados no los afectó en gran medida ${ }^{3}$. En forma análoga, la desaceleración económica a partir de 2008 también afectó de distinta manera a los diversos sectores, así como a sus inversiones.

Algunos sectores se destacan como los principales responsables del aumento de las inversiones en el período. Como se muestra en el cuadro 1, los sectores de petróleo y gas, agroindustria, metalurgia, minería, y

\footnotetext{
${ }^{3}$ La penetración de los productos importados obedeció sobre todo a la apreciación del tipo de cambio y, paralelamente, a la mayor importación de productos asiáticos (en particular, chinos).
} GRÁFICO 2

Brasil: tasa de inversión y utilización de la capacidad instalada, 2003-2013 (Como porcentaje del PIB y en porcentajes, respectivamente)

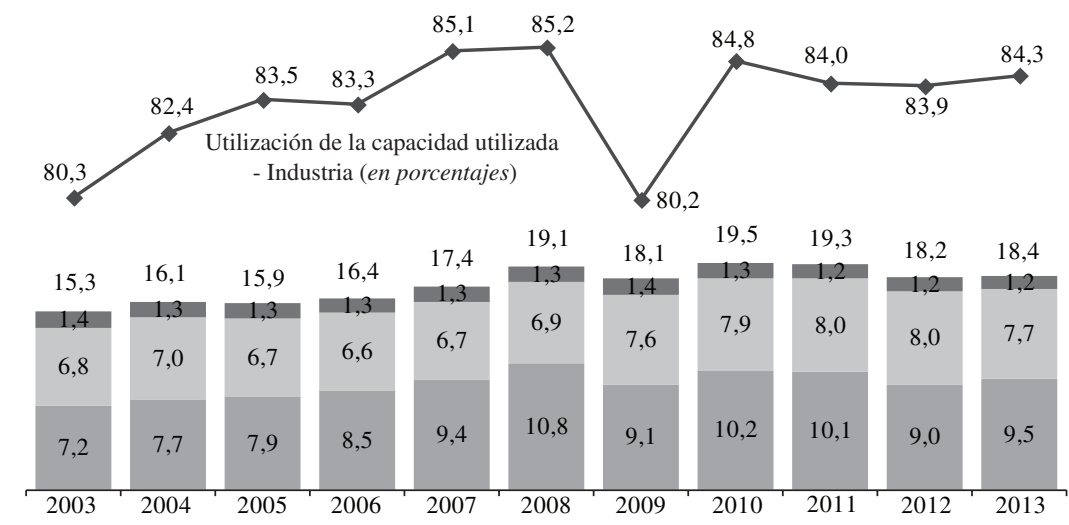

Formación bruta de capital fijo - Otros (como porcentaje del PIB) Formación bruta de capital fijo - Máquinas y equipos (como porcentaje del PIB) - Formación bruta de capital fijo - Construcción (como porcentaje del PIB)

Fuente: Elaboración propia sobre la base de datos del Sistema de Cuentas Nacionales del Instituto Brasileño de Geografía y Estadística (IBGE) y de la Fundación Getulio Vargas.

Nota: PIB: Producto interno bruto. 


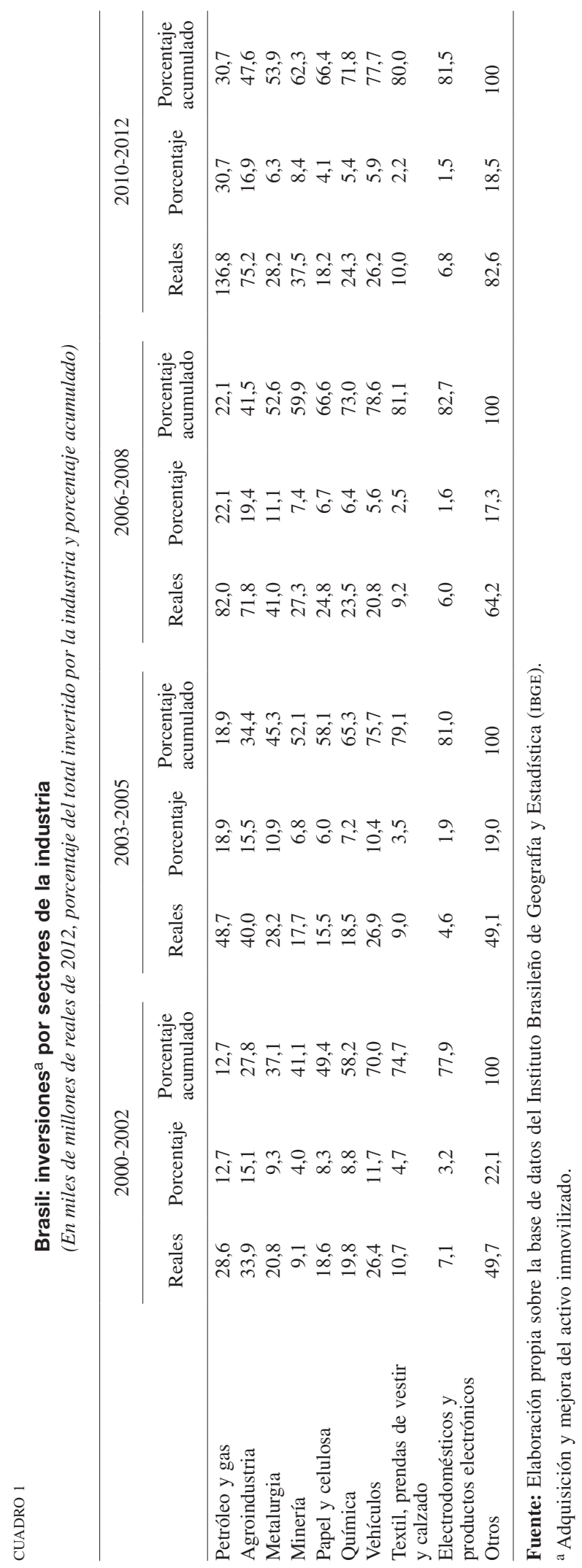


papel y celulosa fueron los principales beneficiarios del ciclo de expansión y presentaron un mayor aumento en las inversiones, sobre todo al comparar el trienio 20032005 con el trienio 2006-2008.

Los sectores de petróleo y gas, agroindustria, metalurgia, minería, y papel y celulosa, que en conjunto representaban menos de la mitad de la inversión total en el trienio 2000-2002, pasaron a representar el 66,6\% en el trienio 2006-2008. Las inversiones de ese grupo de sectores aumentaron de 111.100 millones de reales a 246.900 millones de reales entre el primer y el último trienio analizados (en valores de 2009). Esto supone un incremento del $122,3 \%$ (es decir, un 14,2\% al año).

Sin embargo, la distribución sectorial de las inversiones cambió significativamente después de la crisis de 2008. Mientras que en algunos sectores, como los de petróleo y gas, agroindustria y minería, se mantuvo la tendencia ascendiente de las inversiones (la inversión total creció de 161.100 millones de reales en el trienio 2006-2008 a 249.600 millones de reales en el trienio 2010-2012), en otros, como los sectores de metalurgia, y papel y celulosa, estas disminuyeron considerablemente (la inversión total de esos dos sectores se redujo de 65.800 millones de reales a 46.400 millones de reales en el mismo período). En consecuencia, el período posterior a la crisis se caracterizó por una concentración aún mayor de las inversiones, pues el 56\% de las inversiones de la industria se dirigió a apenas tres sectores: petróleo y gas, agroindustria y minería.

\section{III}

\section{Análisis de la industria de bienes de capital: aspectos metodológicos}

La definición de la industria de bienes de capital es bastante simple y se basa en la funcionalidad de los productos elaborados: los bienes de capital se utilizan para fabricar otros bienes y se distinguen de los insumos porque, a diferencia de estos, se emplean repetidamente y no sufren transformaciones en el proceso productivo.

A pesar de la simplicidad de su definición, la elección de la tipología adoptada para el análisis del sector productor de bienes de capital no es sencilla y tampoco puede ser completa. Al no tratarse de una industria específica, sino de un conjunto de ellas que se unen según la finalidad de los bienes producidos, los resultados del análisis del sector dependen sobre todo de la tipología usada para distinguirla, que debe estar alineada con la finalidad del estudio que se pretende realizar.

\section{Clasificación de la industria de bienes de capital}

La clasificación tradicional segmenta la industria de bienes de capital sobre la base de una característica del proceso productivo de esos bienes: estos pueden producirse por encargo o en serie. La producción de los bienes de capital en serie está estandarizada, sujeta a importantes economías estáticas de escala, y suele exigir - en la mayoría de los casos- escalas mínimas de producción bastante elevadas. Los bienes de capital fabricados por encargo se producen de acuerdo con especificaciones de la industria que los utilizará, en la mayor parte de los casos asociada al productor de esos bienes. Las economías dinámicas de escala, derivadas de la repetición de experiencias de proyección y fabricación de bienes con características similares, son importantes para el buen desempeño de esa industria (Nassif, 2008; Vermulm y Erber, 2002).

Sin embargo, la segmentación presentada resulta insuficiente para los fines de este trabajo. Debido a que se procura analizar el desempeño de la industria de bienes de capital ante las conmociones en la estructura de la demanda, se abandona la clasificación tradicional en favor de una clasificación basada en el segmento demandante. Con esta tipología alternativa se busca captar la segmentación de esa industria de acuerdo con el sector inversor, destacando especialmente la 
dependencia de esos sectores de la producción interna de bienes de capital para la expansión, generación y absorción de tecnología.

En este trabajo, la industria de bienes de capital se divide en cinco grandes grupos sobre la base de la Clasificación Nacional de Actividades Económicas (CNAE) del Instituto Brasileño de Geografía y Estadística (IBGE) ${ }^{4}$. Posteriormente se analizan, dentro del segmento de máquinas y equipos de uso típicamente industrial, las eventuales diferencias que puedan existir en la oferta de bienes de capital de acuerdo con los sectores demandantes.

\section{Estructura, fuente de datos e indicadores utilizados para el análisis}

Con vistas al análisis de la industria de bienes de capital, de sus principales segmentos y de los sectores del segmento de máquinas y equipos de uso típicamente industrial, se examina la evolución de la producción nacional y de la demanda interna. En el primer caso se destaca la fuente de la demanda (mercado interno o externo) y en el segundo, el origen del producto (nacional o importado). Para ello se extrajeron los datos de valor de transformación industrial y valor bruto de la producción industrial de la Encuesta Industrial Anual-Empresa del IBGE (unidad de investigación: unidad local) relativos a los cinco segmentos y los datos de valor de la producción de la Encuesta Industrial Anual-Producto, también del IBGE, relativos a los sectores del segmento de máquinas y equipos de uso típicamente industrial.

Los datos concernientes a las exportaciones y las importaciones, expresados en kilogramos y en dólares, se tomaron de AliceWeb, el sistema de análisis de información de comercio exterior del Ministerio para el Desarrollo, la Industria y el Comercio Exterior (MDIC). Sobre la base de esos datos, se calcularon el consumo aparente (producción sin las exportaciones sumada a las importaciones) y los coeficientes de exportación (relación entre exportaciones y producción) y de penetración de las importaciones (relación entre importaciones y consumo aparente).

En el caso de los sectores que presentaron niveles de exportación e importación relativamente altos, se

\footnotetext{
${ }^{4}$ Véase en el anexo 1 la lista de los sectores que componen los grupos.
}

evalúa el índice de Grubel y Lloyd ${ }^{5}$, con el que se procura medir el carácter interindustrial o intraindustrial del comercio ${ }^{6}$. La evaluación permite determinar si la industria nacional podría o no suministrar los bienes de capital que se han importado. La razón entre el valor unitario de las exportaciones y el valor unitario de las importaciones, medidos en dólares por kilo, permite tener una dimensión de la brecha tecnológica entre los productos nacionales y los importados y establecer si el comercio es horizontal o vertical ${ }^{7}$.

Con esos datos se procura evaluar la capacidad efectiva y potencial de cada segmento de la industria brasileña para suministrar los bienes de capital requeridos por el sector manufacturero nacional. La preocupación por esos indicadores se debe a la sospecha de que gran parte de los bienes importados para la inversión nacional no difiere mucho de los bienes producidos en el país con respecto al nivel tecnológico.

Con este fin se intenta analizar si de hecho la industria nacional no podría satisfacer la demanda interna debido a su falta de desarrollo tecnológico o si —debido al intenso crecimiento de la inversión tras décadas de estancamiento- la insuficiencia de la capacidad instalada en la industria de bienes de capital nacional para satisfacer la demanda habría estimulado la entrada de productos importados, provocando un desfase entre la oferta interna y la demanda de esos bienes. El objetivo principal es localizar los segmentos donde ese hecho es más recurrente y donde la industria de bienes de capital nacional no podría actuar como proveedora de las demás industrias nacionales, incluso desde el punto de vista tecnológico.

\footnotetext{
${ }^{5}$ Calculado para el nivel de ocho dígitos de la Nomenclatura Común del MERCOSUR (NCM).

${ }^{6}$ El índice de Grubel y Lloyd se calcula como la razón entre el módulo de la sumatoria de la diferencia entre exportaciones e importaciones de cada producto en el numerador y la sumatoria de las exportaciones y las importaciones en el denominador. Los valores próximos a la unidad indican la predominancia del comercio intraindustrial y, por el contrario, los valores próximos a cero señalan la predominancia del comercio interindustrial.

${ }^{7}$ De acuerdo con Resende y Anderson (1999), Feltrin (2005) y Baltar (2007), en la literatura económica se considera que el comercio intraindustrial es horizontal cuando la relación entre el valor unitario de las exportaciones y el valor unitario de las importaciones varía de 0,85 a 1,15 y que dicho comercio es vertical en los demás casos.
} 


\section{IV}

\section{Caracterización de la industria de bienes de capital brasileña}

La importancia de la industria de bienes de capital brasileña se refleja en el PIB industrial, que en 2012 alcanzó a 88.300 millones de reales. No menos importante fue su capacidad de generación de empleos: según datos de la Encuesta Industrial Anual-Empresa del IBGE, el 31 de diciembre de 2012 más de 690.000 trabajadores estaban ocupados directamente en las empresas productoras de bienes de capital, cifra que representa el $10,7 \%$ de los trabajadores de la industria de transformación. En ese contexto, el análisis de esa industria requiere la comprensión de los factores que han dinamizado su producción y sus relaciones comerciales.

\section{Caracterización general de la industria de bienes de capital}

En virtud de una demanda cada vez mayor, entre 2003 y 2008 (y sobre todo después de 2006) la producción de la industria de bienes de capital creció por sobre el PIB. El crecimiento del PIB del sector, medido por el valor de transformación industrial, fue del 8,8\% anual en términos reales, mientras que el crecimiento del PIB del país en el período, aunque elevado, no alcanzó al $5 \%$ anual. Aunque a un ritmo menor, la trayectoria de expansión del sector de bienes de capital se mantuvo a pesar de la desaceleración del crecimiento del PIB después de 2008. En términos de producción, por ejemplo, la tasa de crecimiento se redujo al 5,5\% anual entre 2008 y 2012, configurando de ese modo una desaceleración relativa, como se muestra en el gráfico 3 .

El aumento de la producción de bienes de capital en el período 2003-2012 se caracteriza por tres ciclos distintos: en el primero, entre 2003 y 2004, hubo un repentino incremento de la demanda externa de bienes de inversión, de modo que el sector - que presentaba baja capacidad de producción después de muchos años de escasa inversión en la economía brasileña- pasó a utilizar casi toda la capacidad instalada existente. En el segundo, entre 2006 y 2008, se acrecentaron la intensidad y la duración de la demanda interna de máquinas y equipos, garantizando la continuidad de la utilización de la capacidad productiva, lo que se tradujo

GRÁFICO 3

Brasil: producción y empleo en la industria de bienes de capital, 2000-2012

(En miles de millones de reales de $2012^{\mathrm{a}}$ y miles, respectivamente)

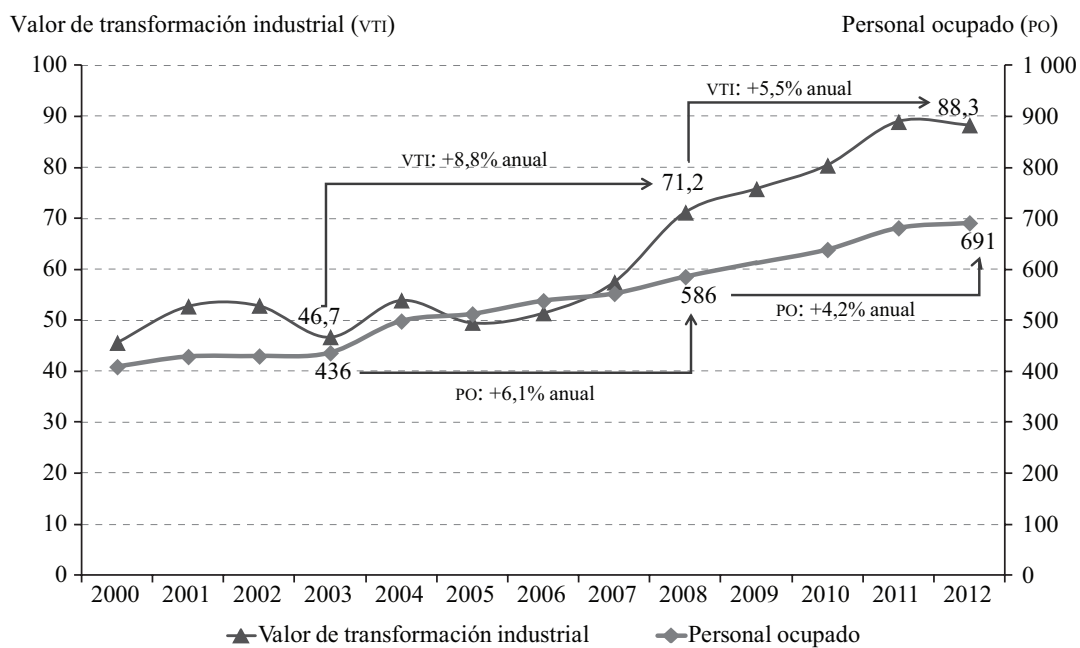

Fuente: Elaboración propia sobre la base de datos del Instituto Brasileño de Geografía y Estadística (IBGE) y la Fundación Getulio Vargas.

a Deflactado mediante el índice de precios al por mayor-oferta global de la Fundación Getulio Vargas correspondiente al sector. Se excluyó el año 2009 para facilitar la visualización. 
en inversiones para el aumento de la capacidad de oferta del sector. Por último, en el tercer ciclo, entre 2008 y 2012, la desaceleración económica y la reducción de las inversiones se tradujeron en una disminución de la tasa de crecimiento del sector de bienes de capital, que pese a la pérdida de dinamismo se mantuvo aún en expansión.

Como se muestra en el gráfico 4, mientras que la inversión del país (medida por el consumo aparente de máquinas y equipos) aumentó ligeramente entre mediados de 2003 y 2004, la utilización de la capacidad instalada de dicho sector alcanzó el mayor nivel de la serie $(85,6 \%)$ en octubre de 2004. Ello obedeció principalmente a la mayor demanda externa de máquinas y equipos, que pasó de 30.600 millones de reales en 2003 a 51.000 millones de reales en $2005^{8}$.

Sin embargo, la situación fue bastante distinta en el período siguiente: a partir de 2006, la inversión en máquinas y equipos creció significativamente en el país y derivó en un aumento de la utilización de la capacidad instalada en la industria de bienes de capital, que se mantuvo a un nivel elevado en los años sucesivos (llegó al 84,6\% en agosto de 2007 y al 84,1\% en julio de

8 Las exportaciones de bienes de capital aumentaron de 20.600 millones de reales a 51.000 millones de reales entre 2000 y 2004 (aumento del $25,4 \%$ al año) y el coeficiente de exportación del sector se incrementó del 32,5\% al 40,0\%, alcanzando un nivel muy superior a su media histórica.
2008, situándose por sobre el 82\% entre enero de 2007 y octubre de 2008).

Después del retroceso del nivel de actividad en 2009 la inversión fue más elevada, pero creció a tasas menores que en el período de pronunciada aceleración. A fines de 2011 la inversión dejó de crecer y, en consecuencia, la utilización de la capacidad del sector, que ni siquiera había alcanzado el nivel anterior a la crisis (manteniéndose siempre por debajo del 82\%), comenzó una trayectoria decreciente.

El aumento de la demanda de bienes de capital entre 2006 y 2008, impulsado principalmente por el incremento de las inversiones industriales y la inversión pública ${ }^{9}$, tuvo importantes efectos en el comercio exterior de bienes de capital del Brasil. La producción nacional de esos bienes — que durante el período de escasa inversión fue objeto de un proceso de racionalización productiva, orientándose fundamentalmente a las exportaciones- se dirigió sobre todo al mercado interno, en particular después de 2005, cuando se incrementó la inversión nacional y el tipo de cambio comenzó a apreciarse (dificultando las exportaciones).

En la medida en que dejó de ocupar la capacidad existente y comenzó a demandar bienes de inversión, el

\footnotetext{
9 De acuerdo con datos del Instituto de Investigación Económica Aplicada (IPEA), la inversión pública (incluida la estatal) aumentó del $2,7 \%$ al 3,7\% del PIB entre 2005 y 2008.
}

GRÁFICO 4

\section{Brasil: consumo aparente y utilización de la capacidad instalada de máquinas y equipos, 2003-2011 \\ (En porcentajes y número índice: promedio $1996=100$, respectivamente)}

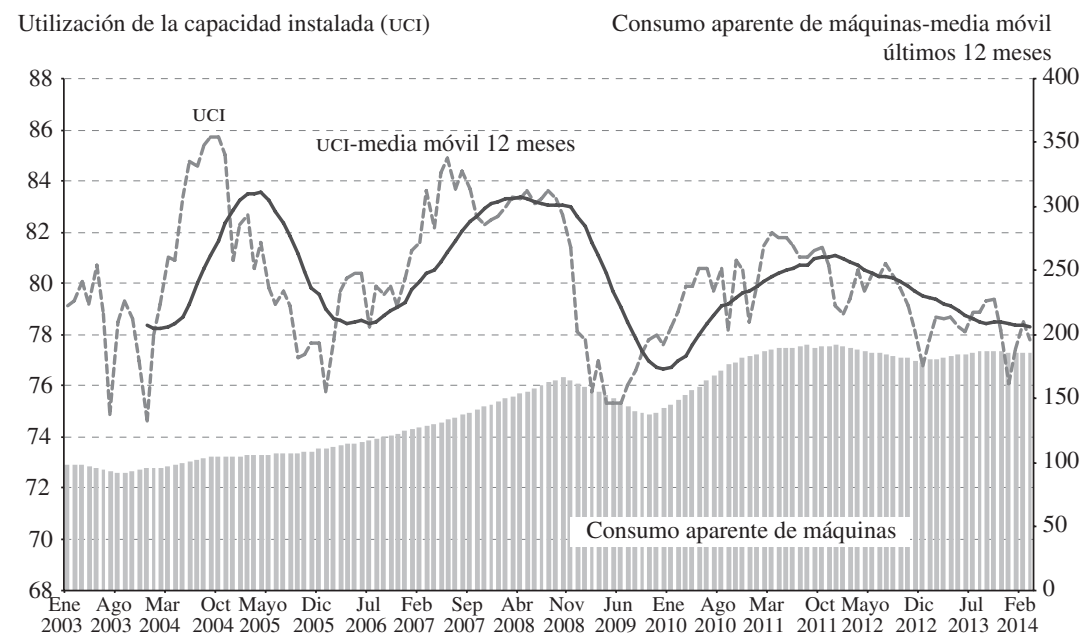

Fuente: Elaboración propia sobre la base de datos del Instituto de Investigación Económica Aplicada (IPEA) y de la Confederación Nacional de la Industria (CNI). 
ciclo de expansión de la economía brasileña de 2003 a 2008 tuvo relevantes repercusiones en la producción y la comercialización interna de bienes de capital. Después de algunas décadas de estancamiento, la perturbación de la demanda hizo que las empresas productoras de máquinas y equipos rápidamente utilizaran casi toda su capacidad productiva y volvieran a emplear, producir y demandar insumos que ayudaron a sostener este ciclo de expansión.

A partir de 2008, debido a la reducción de la tasa de crecimiento del país y al estancamiento de las inversiones, la industria de bienes de capital entró en una nueva dinámica ante la disminución de la demanda de máquinas y equipos por parte del mercado interno. Las exportaciones, que ya habían perdido competitividad en el ciclo 2006-2008, se aminoraron aún más, en este caso debido a la dificultad de acceso a los mercados externos a causa de la desaceleración de la economía a nivel mundial y la apreciación del tipo de cambio. Las importaciones, por otra parte, continuaron evolucionando y perjudicaron acentuadamente la capacidad de crecimiento del sector, lo que se tradujo en un deterioro incluso mayor del saldo comercial.

\section{Principales segmentos de la industria de bienes de capital}

Como se señaló anteriormente, la producción de bienes de capital, medida por el valor de transformación industrial, alcanzó la suma de 88.275 millones de reales en 2012. Se destacan los segmentos de máquinas y equipos de uso típicamente industrial y de equipos de transporte, cuya producción ascendió a 34.126 millones de reales y 24.665 millones de reales, respectivamente. Les sigue el segmento de equipos de informática, electrónicos y ópticos, con una producción de 13.554 millones de reales en 2012. Por último, los segmentos de equipos para el sector de energía eléctrica y máquinas y equipos para la industria agropecuaria, aunque menos relevantes, también registraron una producción significativa de 8.379 millones de reales y 7.551 millones de reales, respectivamente (véase el gráfico 5).

Si bien entre 2003 y 2012 aumentó la producción en todos los segmentos, el proceso y las fases de ese crecimiento se diferencian bastante según el segmento analizado. Como ya se mencionó, la evolución en el primer ciclo se relacionó específicamente con la demanda

GRÁFICO 5

Brasil: valor de transformación industrial (VTI) por segmento, 2000-2012

(En miles de millones de reales de 2012a)

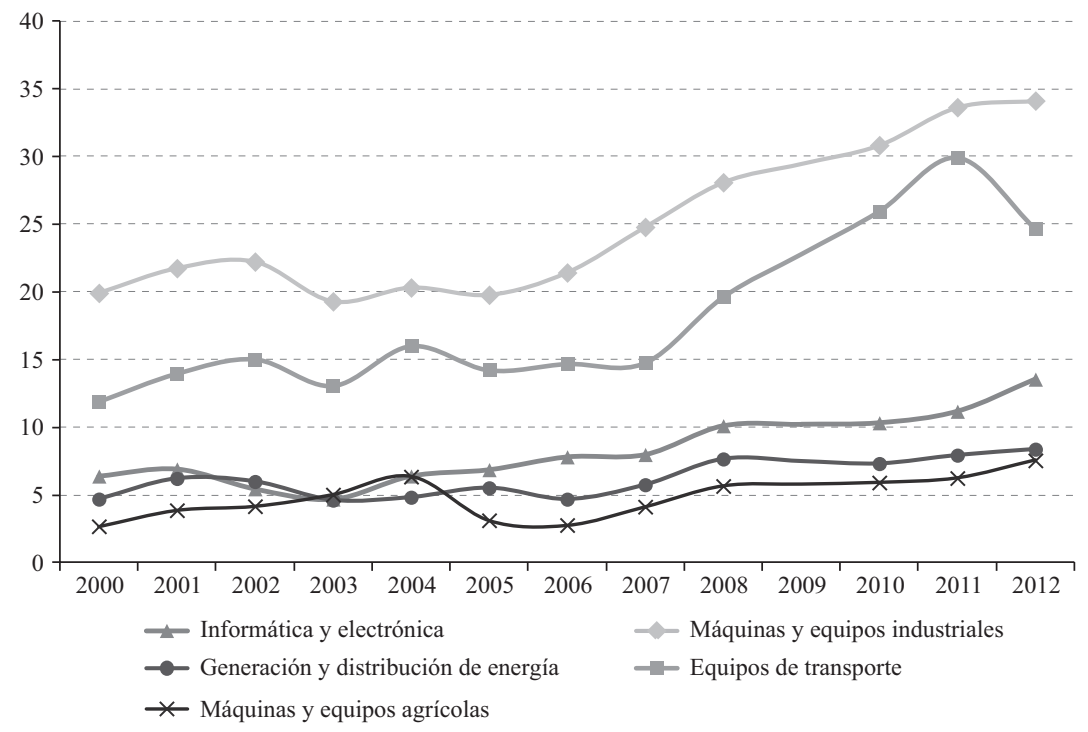

Fuente: Elaboración propia sobre la base de datos del Instituto Brasileño de Geografía y Estadística (IBGE) y la Fundación Getulio Vargas.

a Deflactado mediante el índice de precios al por mayor-oferta global de la Fundación Getulio Vargas correspondiente al sector. Se excluyó el año 2009 para facilitar la visualización. 
externa. No es casual que los segmentos más orientados a la exportación (equipos de informática, electrónicos y ópticos, máquinas y equipos agrícolas y equipos de transporte) registraran el mayor crecimiento en 2004 (aunque también evolucionaron en el ciclo siguiente) ${ }^{10}$.

La evolución en el segundo ciclo (entre 2006 y 2008) estuvo más relacionada con la expansión del mercado interno y, en particular, con las inversiones industriales. En ese sentido, el desarrollo de los segmentos productores de máquinas y equipos de uso típicamente industrial y de equipos para el sector de energía eléctrica, que se caracterizan por la gran importancia de su demanda interna, se concentró en la segunda mitad de la década de 2000 .

A partir de 2008, los segmentos de la industria de bienes de capital ligados al mercado externo encontraron aún más dificultades para expandirse, pues a la apreciación del tipo de cambio — que limitó su desarrollo en el ciclo anterior - se sumó la merma de la demanda de sus socios comerciales. En tal sentido, el período posterior a la crisis se caracterizó por una expansión impulsada por el mercado interno, pero con mucho menos dinamismo que en el ciclo anterior.

Como se muestra en el gráfico 6, en el que se descompone el aumento de la producción total (medido por el valor bruto de la producción industrial) en exportaciones

\footnotetext{
${ }^{10}$ Con excepción del segmento de equipos de informática, electrónicos y ópticos, que presenta una marcada dependencia del mercado interno, pero que - debido a que suministra equipos a sectores exportadorescreció casi continuamente en el período de 2003 a 2012.
}

y demanda interna, el crecimiento del sector de bienes de capital entre 2002 y 2004 se explica en gran medida por la demanda externa. En los segmentos productores de equipos de transporte y máquinas y equipos agrícolas, cuyas tasas de crecimiento nominales fueron del $81 \%$ y el $114 \%$, respectivamente en ese período, más de la mitad de la expansión se debió directamente a la demanda externa. Lo mismo ocurrió en el sector de máquinas y equipos de uso típicamente industrial, que sin embargo presentó un crecimiento mucho más relevante en el segundo y tercer ciclos, cuando la demanda de bienes de inversión obedeció sobre todo a la inversión interna.

Además de los efectos en la producción analizados anteriormente, el aumento de la inversión, sobre todo después de 2006, tuvo un efecto significativo en las importaciones, potenciado por la mayor utilización de la capacidad instalada (que hizo inviable el incremento de la producción del país) y por la apreciación del tipo de cambio (que facilitó la penetración de los productos importados).

En el gráfico 7 se puede observar que las importaciones cubrieron gran parte del aumento de la demanda interna de bienes de capital, tanto en el segundo ciclo (2005-2008) como en el ciclo posterior a la crisis (2008-2012). En los segmentos de máquinas y equipos de uso típicamente industrial y de equipos de informática, electrónicos y ópticos, las importaciones fueron más relevantes. En el sector de máquinas y equipos típicamente industriales, dado el alto nivel de utilización de la capacidad de la industria brasileña en el segundo ciclo, las importaciones complementaron la oferta nacional en algunos casos,

GRÁFICO 6

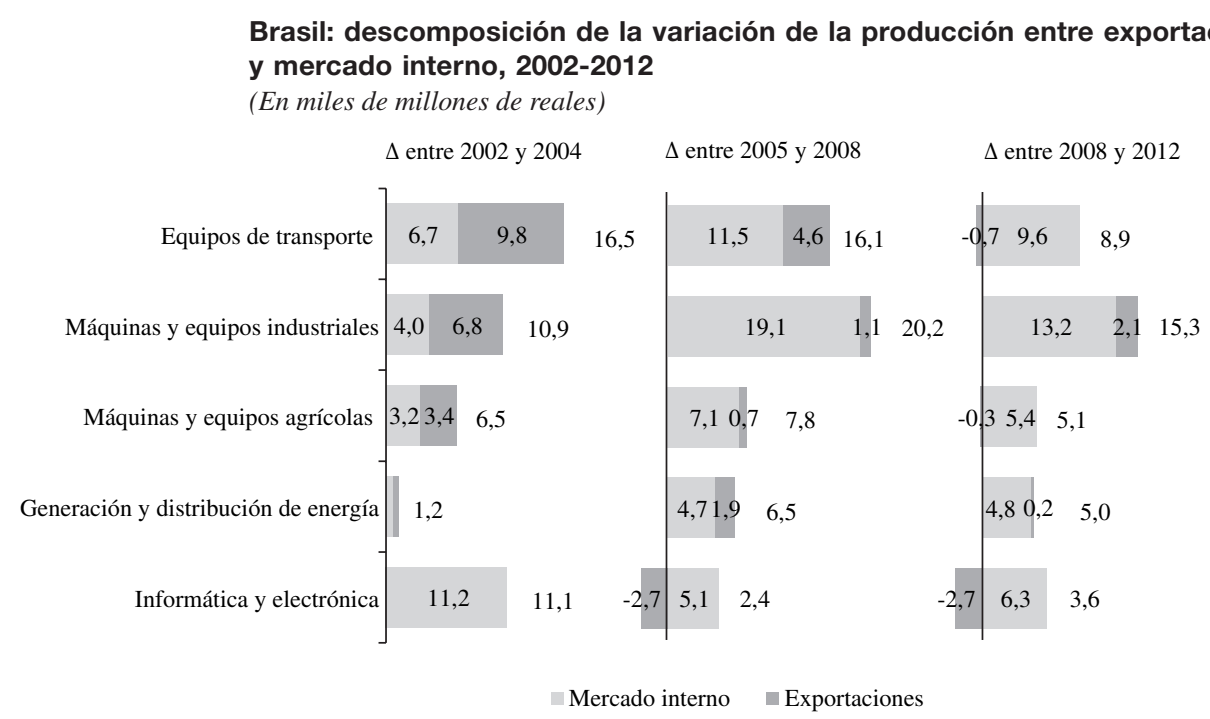

Fuente: Elaboración propia sobre la base de datos de AliceWeb del Ministerio para el Desarrollo, la Industria y el Comercio Exterior. 


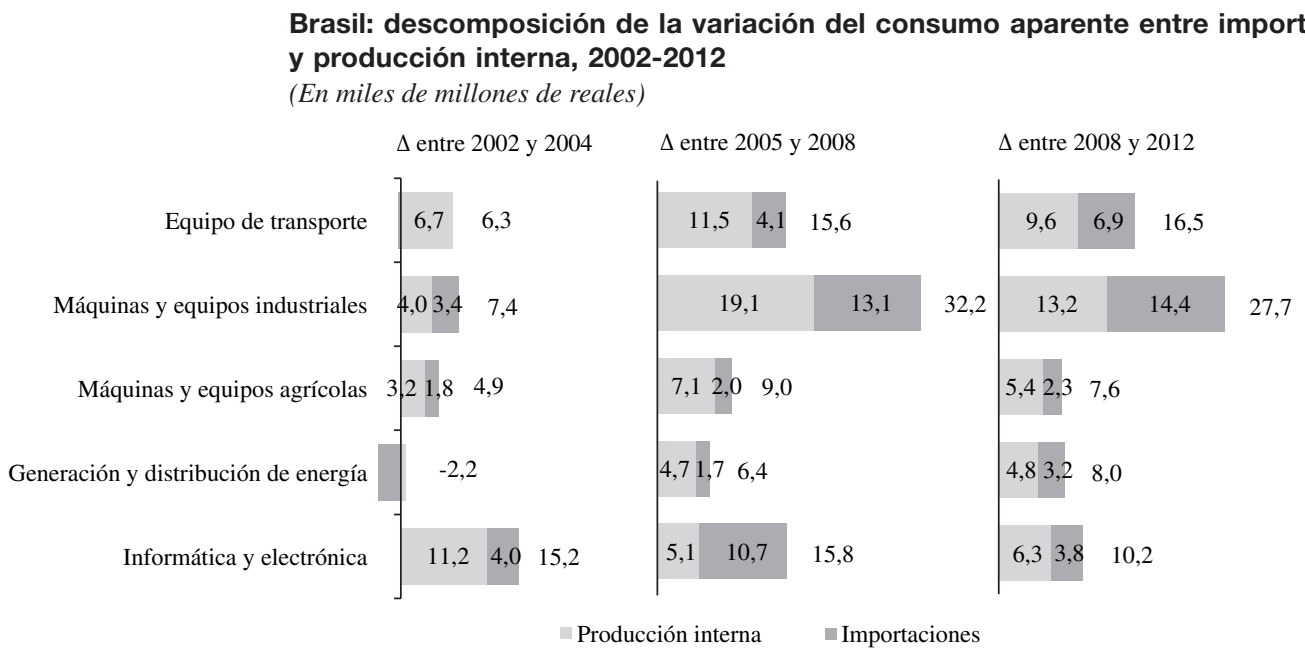

Fuente: Elaboración propia sobre la base de datos del Instituto Brasileño de Geografía y Estadística (IBGE) y AliceWeb del Ministerio para el Desarrollo, la Industria y el Comercio Exterior.

mientras que en otros terminaron por sustituirla. En el caso de los equipos de informática, electrónicos y ópticos, la producción interna fue en gran parte sustituida por las importaciones, no obstante la capacidad productiva ociosa en el segmento ${ }^{11}$. En este rubro de la industria de bienes de capital, que fue sin duda el más afectado por las importaciones, el abaratamiento de los productos importados y la apreciación de la moneda brasileña en términos reales redujeron la competitividad interna y externa de la producción nacional, haciendo inviable la expansión de esa industria en el país. No obstante, al tratarse de un segmento compuesto mayormente por piezas y componentes de otras máquinas y equipos, la sustitución de la oferta interna por la importación de bienes más baratos puede considerarse también como una oportunidad para la expansión de los demás sectores.

En los otros tres segmentos (equipos de transporte, equipos para la generación y distribución de energía eléctrica, y máquinas y equipos agrícolas), las importaciones tuvieron un peso menos relevante en la demanda de bienes de inversión, a pesar de que en la industria nacional se utilizara casi toda la capacidad de producción ${ }^{12}$.

\footnotetext{
${ }^{11}$ De acuerdo con datos de la Fundación Getulio Vargas, el aumento de la utilización de la capacidad instalada en los sectores de material eléctrico y comunicación tuvo lugar entre 2002 y 2005 , cuando pasó del $65,4 \%$ al $80,3 \%$. Posteriormente se mantuvo en alrededor del $80 \%$ y solo se redujo en el período de la crisis de 2008.

12 En el ramo "máquinas y aparatos para producción y distribución de energía eléctrica", la utilización de la capacidad instalada llegó al 90,3\% en 2007 (el mayor nivel por lo menos desde la década de
}

El análisis de la industria de bienes de capital según los principales segmentos permite concluir que se trata de una industria bastante heterogénea, afectada diversamente por la perturbación de la demanda a raíz del ciclo de expansión reciente de la economía brasileña y por la inversión del ciclo en el período posterior a la crisis.

Los segmentos productores de máquinas y equipos para la agricultura y de equipos de transporte crecieron en los tres períodos del ciclo: inicialmente (2003-2004) estimulados por las exportaciones y, a posteriori (20062008 y 2008-2012), por el aumento de la inversión interna. En esos rubros, así como en el de generación y distribución de energía eléctrica (cuya demanda creció solo en el segundo y tercer períodos), se logró cubrir el incremento de la demanda interna. Las importaciones no los afectaron de manera considerable y, una vez alcanzado el máximo nivel de utilización de la capacidad instalada, comenzaron a realizar inversiones significativas que contribuyeron a mantener su posición como principales proveedores del mercado interno. La desaceleración del período posterior a la crisis no alteró esa dinámica, pero redujo su intensidad: esos segmentos continuaron expandiéndose impulsados por el mercado interno,

1990), mientras que en el segmento de material de transporte alcanzó al 88,5\% en 2005 y se mantuvo en ese nivel en los años siguientes. Por último, en los ramos de equipos para la agricultura e industriales rurales y de tractores y máquinas para la realización de terraplenes, la utilización de la capacidad instalada aumentó notablemente en 2004, para luego disminuir y volver a aumentar entre 2007 y 2008, cuando alcanzó niveles elevados con respecto a sus antecedentes. 
aunque a tasas de crecimiento inferiores, al tiempo que aumentó la penetración de los productos importados.

Las condiciones para el sector de equipos de informática, electrónicos y ópticos fueron mucho menos favorables: a diferencia de los demás sectores, la expansión registrada en el período de 2003 y 2004 no se debió a las exportaciones, sino al mercado interno. A partir de 2005, la demanda interna comenzó a satisfacerse sobre todo por las importaciones, que sustituyeron a la oferta interna y desalentaron las inversiones.

Por último, el segmento de máquinas y equipos de uso típicamente industrial es el que se encuentra en condiciones más antagónicas: estimulado sobre todo por la demanda interna en el segundo período, se aprovechó de ella para crecer sustancialmente, pero no logró cubrirla por completo. En 2007, cuando se utilizó casi la totalidad de la capacidad de producción, gran parte de la demanda interna fue satisfecha por las importaciones, favorecidas por la apreciación cambiaria. La situación se volvió aún más desfavorable después de la crisis, dado que la mayor penetración de los productos importados derivó en una reducción de las inversiones del sector, poniendo en duda su capacidad de cubrir la futura expansión de la demanda de la economía brasileña, como se analizará a continuación.

\section{La industria de máquinas y equipos y las inversiones industriales}

Según los datos del IBGE, los segmentos más importantes en la inversión industrial fueron los siguientes: petróleo y gas, agroindustria, minería y, hasta 2008, papel y celulosa, y metalurgia. Esos sectores, que en conjunto representaron el 49,4\% de la inversión en el trienio 20002002 , pasaron a representar el 66,6\% de la inversión en el trienio 2006-2008. En total, esas industrias duplicaron con creces sus inversiones en seis años, incrementándolas a una tasa media del $16 \%$ anual, mientras que las demás las redujeron a una tasa media del 2,1\% al año. La concentración de las inversiones continuó después de 2008, pero solo en los sectores de petróleo y gas, agroindustria, y minería, que representaban el 48,9\% de la inversión en el trienio 2006-2008 y alcanzaron el $56,0 \%$ en el trienio 2010-2012.

El contexto de expansión de las inversiones en algunos sectores después de un largo período de estancamiento - acompañado de una expansión más restringida o incluso de una contracción en otrosconfiguró algunas importantes diferencias en el sector de máquinas y equipos de uso típicamente industrial, las que merecen destacarse y analizarse. En esta subsección se procura analizar la industria de máquinas y equipos proveedora de los sectores que más ampliaron sus inversiones, con miras a evaluar las restricciones que la economía brasileña puede sufrir en caso de mantenerse la trayectoria de expansión basada en esos sectores.

a) Máquinas y equipos para la extracción y prospección de petróleo

El segmento productor de máquinas y equipos para la extracción y prospección de petróleo ${ }^{13}$ destina su producción casi exclusivamente al mercado interno (véase el gráfico 8). No es casual que la producción de este ramo quedara prácticamente estancada hasta $2004^{14}$, incluso pese al aumento del coeficiente de exportación del 8,8\% en 2000 al 18,0\% en 2004. Sin embargo, a partir de 2005, con el crecimiento del consumo interno, la producción del sector para el mercado nacional comenzó a aumentar y derivó en una reducción del coeficiente de exportación del 18,0\% al 13,8\% entre 2004 y 2012 (no obstante un aumento en 2009). Del incremento de 5.010 millones de reales en la producción del sector entre 2004 y 2012, solo 605 millones de reales (12\%) correspondieron a la demanda externa, mientras que los restantes 4.400 millones de reales (el 88\% de la producción) se destinaron al mercado interno.

Si bien las importaciones aumentaron en el período examinado, el coeficiente de penetración de las importaciones (en términos corrientes) se mantuvo prácticamente estable en un nivel relativamente bajo (del 25,6\% en 2005 pasó al 25,7\% en 2008 y al 24,9\% en 2012). Se puede decir, por lo tanto, que la demanda del sector de extracción y prospección de petróleo fue satisfecha en gran medida por la industria nacional, pese a que el aumento de los productos importados no es despreciable.

Cabe destacar que, no obstante los coeficientes de penetración de los productos importados se hayan mantenido estables, el sector presenta un elevado comercio intraindustrial, que se ha verticalizado cada vez más a favor de la industria nacional. Esto significa que

\footnotetext{
${ }^{13}$ El IBGE clasifica los sectores de la actividad económica brasileña de acuerdo con la llamada Clasificación Nacional de Actividades Económicas (CNAE), de la que hay dos versiones: CNAE 1.0 y CNAE 2.0. Además de los productos de la actividad 2851 (CNAE 2.0), que se refiere a las máquinas y los equipos para extracción y prospección de petróleo, están incluidos también otros productos que en su mayoría se destinan a esta actividad: 2813.2040, 2813.2050, 2813.2030, 2813.2060, 2813.2090, 2813.2100, 2813.2080, 2813.2110, 2813.2070, 2813.2130, 2813.2010 (CNAE 2.0).

${ }^{14}$ Deflactada mediante el índice de precios al por mayor-oferta global, de la Fundación Getulio Vargas, la producción del sector creció un $8,7 \%$ entre 2000 y 2004 ( $2,1 \%$ anual).
} 

productores de máquinas y equipos para la extracción y prospección de petróleo, 2000-2012

(En millones de reales)

Producción por destino

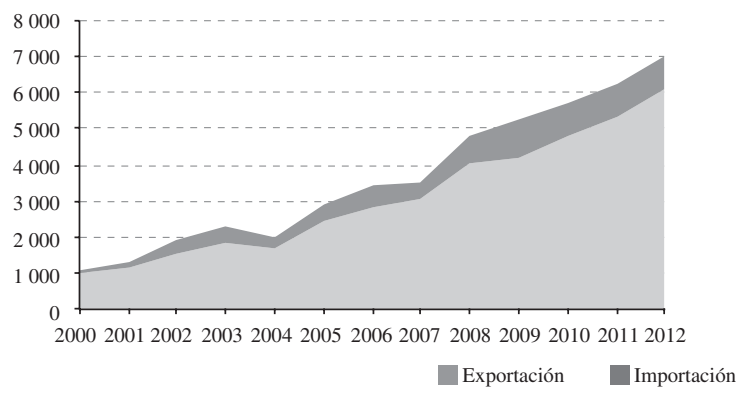

Consumo aparente por origen

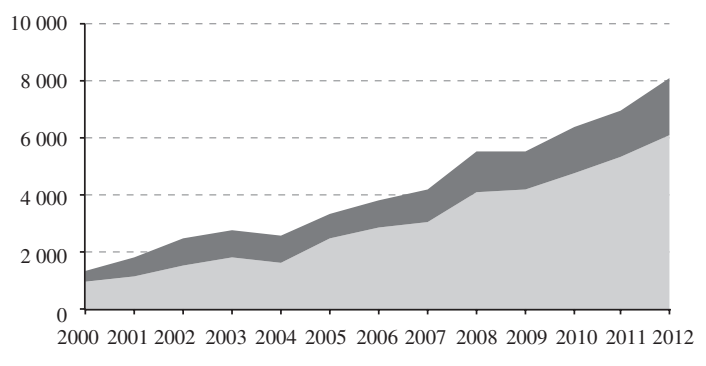

Fuente: Elaboración propia sobre la base de datos del Instituto Brasileño de Geografía y Estadística (IBGE) y AliceWeb del Ministerio para el Desarrollo, la Industria y el Comercio Exterior.

se compone cada vez más de productos con diferentes valores tecnológicos y que el producto nacional tiene un mayor contenido tecnológico con respecto al importado ${ }^{15}$. Eso indica que la industria nacional ha podido absorber gran parte del aumento de la demanda, en particular la demanda de máquinas más sofisticadas desde el punto de vista tecnológico.

\section{b) Máquinas y equipos para la minería y la construcción}

A diferencia del segmento de máquinas y equipos para la extracción y prospección de petróleo, las exportaciones constituyen una importante fuente de demanda para el segmento de máquinas y equipos para la minería y la construcción (véase el gráfico 9). Sobre esa base, la producción del rubro aumentó considerablemente ya en la primera mitad de la década de 2000 (un 43,6\% en términos reales entre 2002 y 2004), impulsada sobre todo por la demanda externa, de manera que el coeficiente de exportación se incrementó del 42,6\% en 2000 al 60,7\% en 2004.

Sin embargo, a partir de 2004 el mercado interno también comenzó a cobrar importancia en la demanda de

15 A pesar de la ligera contracción reciente (de 0,56 en 2008 a 0,46 en 2012), el índice de Grubel y Lloyd del sector es relativamente alto en virtud de la estructura tecnológica brasileña vigente en el período de referencia. Esto indica un elevado comercio intraindustrial. La relación entre el valor unitario de las exportaciones y el valor unitario de las importaciones aumentó de 0,43 a 1,03 en 2008, lo que indica que el sector dejó de ser vertical y pasó a ser horizontal. Esa relación continuó evolucionando y alcanzó a 1,58 en 2012, de modo que el comercio volvió a ser vertical, pero en este caso el producto nacional es más avanzado tecnológicamente (véase el anexo 2). esos bienes, en especial después de la crisis, lo que derivó en la reducción del coeficiente de exportación a un nivel próximo al 45\% en 2012. El consumo interno empezó a presionar la demanda, que creció a tasas superiores a la capacidad de oferta del sector ${ }^{16}$. Pese a exportar bastante, este no logró satisfacer la demanda interna. En ese sentido, la dependencia de la oferta importada provocó un aumento sustancial de las importaciones (un 435\% entre 2004 y 2008, medido en reales) y, en consecuencia, del coeficiente de penetración de las importaciones, que pasó del 30,2\% al 42,0\% entre 2004 y 2008 y llegó al 43,7\% en 2012.

En ese contexto, se observa que el sector de máquinas y equipos para la minería y la construcción contaba con el potencial tecnológico para satisfacer la demanda interna, dada la verticalización del comercio en favor del producto nacional, pero no pudo absorberla totalmente debido al aumento desproporcionado de esa demanda entre 2006 y 2011, que trajo aparejado un incremento de las importaciones.

\footnotetext{
${ }^{16}$ Esa sustitución de la oferta del producto nacional por el importado, debido a la falta de capacidad de oferta de la industria nacional, resulta evidente al analizar el índice de Grubel y Lloyd del sector, que aumentó de 0,20 a 0,40 entre 2004 y 2008, y se mantuvo en ese nivel a partir de entonces, lo que demuestra una intensificación del comercio intraindustrial. A su vez, ese comercio intraindustrial era predominantemente horizontal hasta 2008, dada la proximidad de la relación entre el valor unitario de las exportaciones y el valor unitario de las importaciones (de 0,90 en 2004 aumentó a 1,12 en 2008), pero pasó a ser verticalizado en favor de la oferta nacional (la relación entre el valor unitario de las exportaciones y el valor unitario de las importaciones llegó a 1,43 en 2012) (véase el anexo 2).
} 
GRÁFICO 9

Brasil: producción por destino y consumo aparente por origen de los sectores productores de máquinas y equipos para la minería y la construcción, 2000-2012 (En millones de reales)
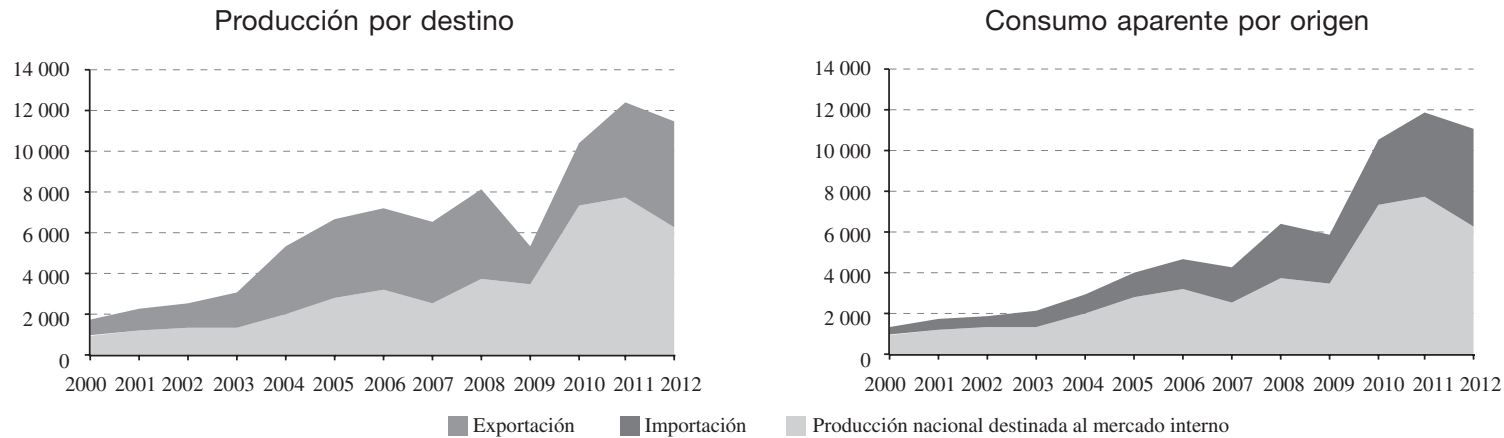

Fuente: Elaboración propia sobre la base de datos del Instituto Brasileño de Geografía y Estadística (IBGE) y AliceWeb del Ministerio para el Desarrollo, la Industria y el Comercio Exterior.

c) Máquinas y equipos para la industria de alimentos, bebidas y tabaco

La producción nacional de máquinas y equipos para la industria de alimentos, bebidas y tabaco se destina casi exclusivamente al mercado interno (véase el gráfico 10). Esta industria presenta un bajo coeficiente de exportación (alrededor del 15\% hasta 2006, disminuyendo al 6,8\% en 2008), y no fue casual que se expandiera sobre todo en la segunda mitad de la década de 2000, estimulada por el mercado interno.

El aumento de la inversión de los sectores agroindustriales promovió un incremento de la producción del sector del 19,3\% (en términos reales) en 2005 y del $68,4 \%$ entre 2006 y 2008. El crecimiento de la demanda fomentó el desarrollo de las importaciones, que se triplicaron con creces en el período 2004-2008 ${ }^{17}$. Sin embargo, debido a la apreciación del real y al acrecentamiento proporcional del consumo aparente, esto no se tradujo en un incremento del coeficiente de penetración de las importaciones, que - después de disminuir del $29,8 \%$ al $15,5 \%$ entre 2000 y 2004 - se mantuvo en alrededor del 15\% entre 2004 y 2008.

${ }^{17}$ El aumento, medido en reales, kilogramos y dólares, fue de 197\%, $213 \%$ y $374 \%$, respectivamente.

GRÁFICO 10

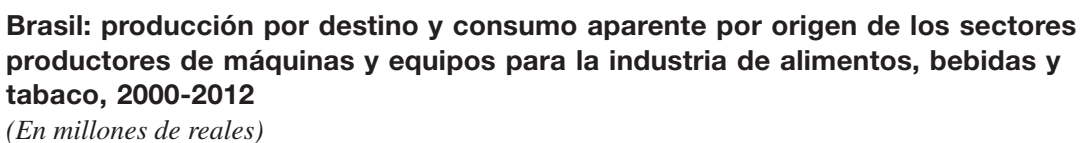

Producción por destino

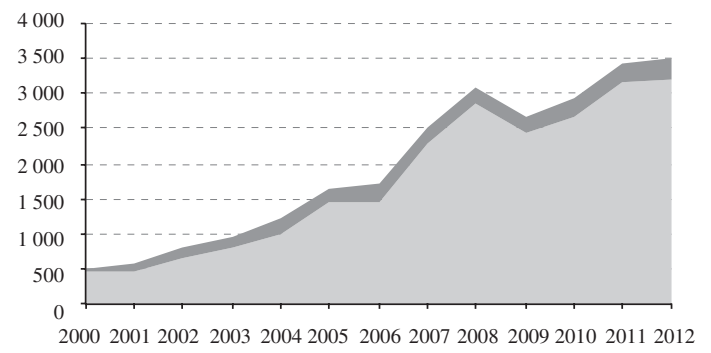

Exportación Importación
Consumo aparente por origen

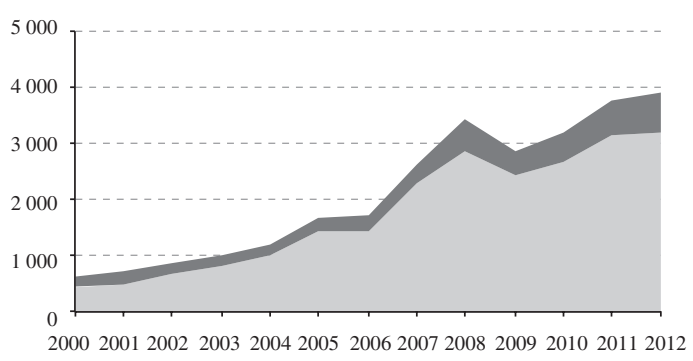

Producción nacional destinada al mercado interno

Fuente: Elaboración propia sobre la base de datos del Instituto Brasileño de Geografía y Estadística (IBGE) y AliceWeb del Ministerio para el Desarrollo, la Industria y el Comercio Exterior. 
A partir de ese último año, la desaceleración de las inversiones repercutió considerablemente en el sector de máquinas y equipos para la industria de alimentos, cuya producción en términos reales fue menor en 2012 que en 2008. Pese al notorio aumento del coeficiente de importación, la merma de la producción del sector no se debe al factor competitividad, sino a la contracción de la demanda.

d) Máquinas y equipos para las industrias productoras de papel y celulosa

Aunque presenta un alto coeficiente de exportación, la industria brasileña de máquinas y equipos para la producción de papel y celulosa quedó prácticamente estancada durante la primera mitad de la década de 2000 , pues creció apenas un 3,8\% en términos reales entre 2002 y 2005. En ese período, la situación de esta industria no empeoró solo gracias a las exportaciones, que se triplicaron con creces (tanto en kilogramos como en dólares ${ }^{18}$ ) y sustentaron la expansión en dicho período (véase el gráfico 11).

A diferencia de los demás segmentos analizados, el desarrollo del mercado interno de máquinas y equipos para la industria productora de papel y celulosa se concentró en el año 2007, cuando el consumo aparente (que era prácticamente estable) aumentó un 89,3\%. No obstante, ese incremento de la demanda supuso una considerable pérdida de mercado en favor de los

${ }^{18} \mathrm{El}$ resultado en reales es menos significativo, especialmente debido a la devaluación de la moneda entre 2002 y 2003 . Sin embargo, entre 2003 y 2005 el aumento en el sector fue del $85 \%$. productos importados, como demuestra el coeficiente de penetración de las importaciones, que creció, incluso en términos corrientes, del $26,4 \%$ al $36,3 \%$.

Asimismo, el índice de Grubel y Lloyd del sector en $2007(0,29)$ demuestra que el comercio era predominantemente interindustrial ${ }^{19}$. En ese sentido, la oferta interna del sector de máquinas y equipos para las industrias del papel y la celulosa no logró absorber el crecimiento de la demanda interna, debido tanto a la falta de capacidad de producción como a la escasa diversificación de los bienes producidos.

\section{e) Máquinas y equipos para la metalurgia, excepto máquinas herramientas}

Si bien las exportaciones crecieron al comienzo del ciclo de expansión posterior a 2003, el segmento de máquinas y equipos para la metalurgia se mantuvo casi estancado ${ }^{20}$ (véase el gráfico 12). Sin embargo, debido a un considerable aumento de la demanda interna, la producción del sector se acrecentó un 84,2\% en términos reales entre 2005 y 2006 . Ese incremento de la producción no bastó para satisfacer la demanda interna, en especial porque los bienes ofrecidos por las empresas nacionales eran tecnológicamente inferiores con respecto a los importados (tenían menor valor unitario), y el comercio fue predominantemente interindustrial

\footnotetext{
19 Véase el anexo 2.

${ }^{20}$ Entre 2002 y 2004, la producción del sector se redujo un 30,1\% en términos reales (valor de la producción deflactado mediante el índice de precios al por mayor-oferta global-máquinas y equipos, de la Fundación Getulio Vargas).
}

\begin{abstract}
Brasil: producción por destino y consumo aparente por origen de los sectores productores de máquinas y equipos para las industrias productoras de papel y celulosa, 2000-2012

(En millones de reales)
\end{abstract}

Producción por destino

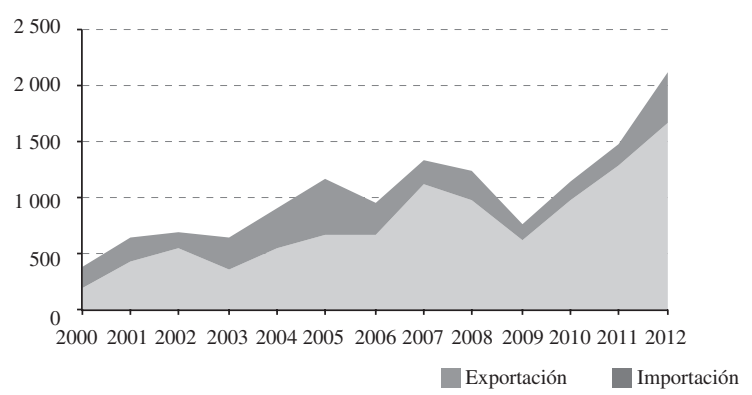

Consumo aparente por origen

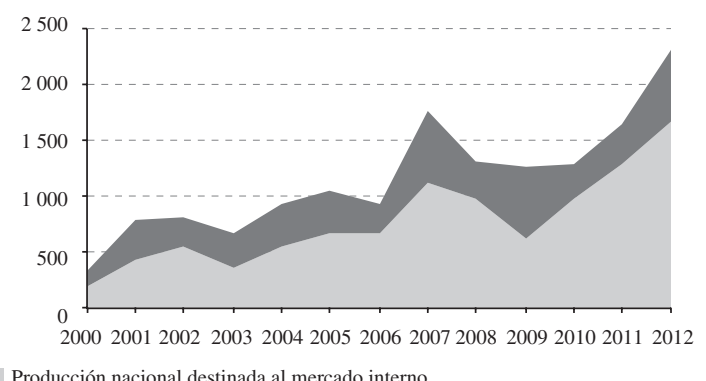

Fuente: Elaboración propia sobre la base de datos del Instituto Brasileño de Geografía y Estadística (IBGE) y AliceWeb del Ministerio para el Desarrollo, la Industria y el Comercio Exterior. 
Brasil: producción por destino y consumo aparente por origen de los sectores productores de máquinas y equipos para la metalurgia, excepto máquinas herramientas, 2000-2012

(En millones de reales)

Producción por destino

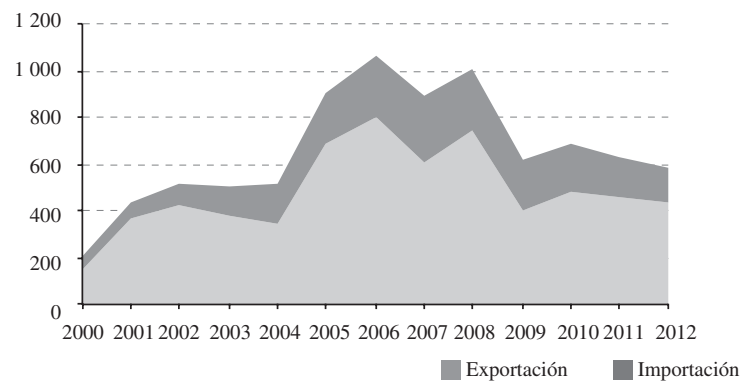

Consumo aparente por origen

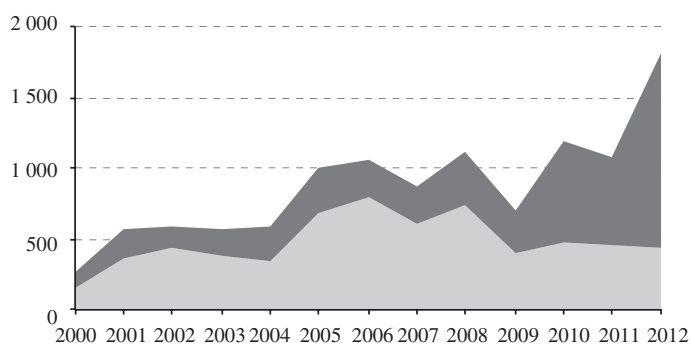

Producción nacional destinada al mercado interno

Fuente: Elaboración propia sobre la base de datos del Instituto Brasileño de Geografía y Estadística (IBGE) y AliceWeb del Ministerio para el Desarrollo, la Industria y el Comercio Exterior.

y vertical ${ }^{21}$. En consecuencia, el aumento de la demanda interna de bienes de capital de la industria metalúrgica, sobre todo en el año 2008, se cubrió en gran medida con la oferta extranjera, pues la oferta interna tenía poca capacidad para sustituirla.

A partir de 2008, la inferioridad tecnológica del producto nacional se volvió aún más evidente y el estancamiento de las inversiones del sector metalúrgico

${ }^{21}$ En 2008, el índice de Grubel y Lloyd del segmento de máquinas y equipos para la industria metalúrgica era de 0,28 y la relación entre el valor unitario de las exportaciones y el valor unitario de las importaciones era de 0,41. Esto indica la predominancia de un comercio interindustrial y vertical (véase el anexo 2). perjudicó aún más a la industria nacional de equipos para la metalurgia. El coeficiente de penetración de las importaciones alcanzó el 76,1\% en 2012 y la industria nacional, que ya estaba estancada desde 2006, comenzó a retroceder.

f) Máquinas y equipos para las industrias textil, de prendas de vestir y calzado

La industria de máquinas para la producción de prendas de vestir, calzado y productos textiles se mantuvo prácticamente estancada en todo el ciclo de expansión de la economía (véase el gráfico 13). Si bien las exportaciones crecieron en forma relativa hasta 2003, comenzaron a declinar en 2004 y el mercado interno no

Brasil: producción por destino y consumo aparente por origen de los segmentos productores de máquinas y equipos para las industrias textil, de prendas de vestir y calzado, 2000-2012

(En millones de reales)

Producción por destino

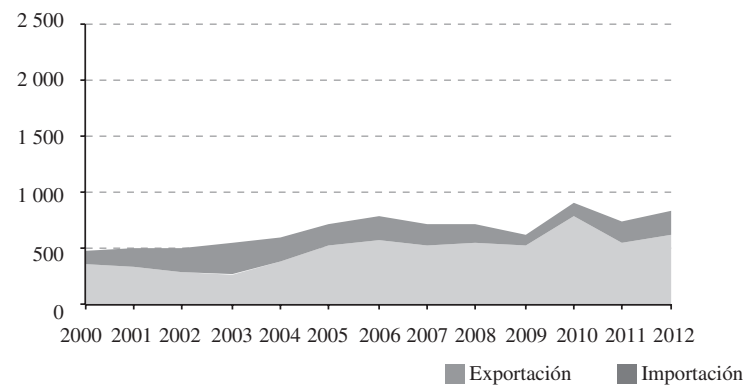

Consumo aparente por origen

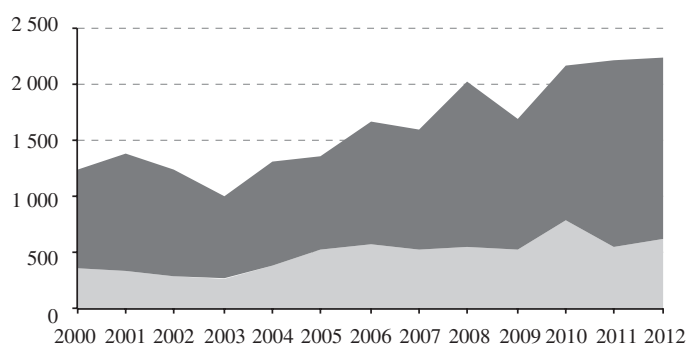

Producción nacional destinada al mercado interno

Fuente: Elaboración propia sobre la base de datos del Instituto Brasileño de Geografía y Estadística (IBGE) y AliceWeb del Ministerio para el Desarrollo, la Industria y el Comercio Exterior. 
logró sostener la demanda de maquinaria nacional. El aumento del mercado interno, aunque poco significativo, fue casi completamente absorbido por las importaciones ${ }^{22}$. Esto supuso un incremento del coeficiente de penetración de las importaciones del sector, que ya era elevado, del 60,8\% en 2005 al 72,4\% en 2008.

En ese contexto, la industria nacional de máquinas y equipos para la producción de textiles, prendas de vestir y calzado resultó incapaz de satisfacer la demanda de los sectores relacionados, tanto en términos efectivos como potenciales. Esto indica una dependencia casi total de las importaciones de maquinaria para su expansión.

\section{g) Síntesis de los resultados de la industria de máquinas y equipos industriales ${ }^{23}$}

Los resultados del sector de máquinas y equipos industriales varían según los segmentos y períodos analizados. Se pueden distinguir tres períodos de mayor divergencia: el primero, de 2002 a 2004, se caracteriza por un crecimiento basado sobre todo en las exportaciones; en el segundo, de 2005 a 2008, la expansión fue más duradera y generalizada entre los diversos sectores; y en el tercero, de 2008 a 2012, la demanda continuó creciendo en algunos sectores y comenzó a declinar en otros.

La principal fuente de demanda en el primer período fue el mercado externo. En esos años, se destacaron el segmento productor de máquinas y equipos para la minería y la construcción — que se desarrolló en forma considerable - y el segmento proveedor de las industrias productoras de papel y celulosa, cuyo crecimiento, aunque menos intenso, se debió casi exclusivamente al mercado externo.

$\mathrm{Al}$ contrario del anterior, la principal fuente de demanda en el segundo período fueron las inversiones industriales realizadas internamente. Si bien estas estimularon la producción de sectores orientados al mercado interno, también favorecieron la penetración de productos importados. A excepción del ramo productor de máquinas y equipos para las industrias textil, de prendas de vestir y calzado, cuya demanda interna fue absorbida casi completamente por las importaciones debido a la escasa diversificación de la oferta, todos

\footnotetext{
22 Entre 2005 y 2008 (principal período de crecimiento de la inversión del sector), el consumo aparente del sector aumentó 656 millones de reales, de los cuales 632,6 millones (el 96\%) fueron absorbidos por las importaciones.

${ }^{23}$ Véase la síntesis de los resultados por período en el cuadro del anexo 3.
}

los segmentos analizados aprovecharon esa demanda para expandirse.

Por último, la principal fuente de demanda en el tercer período fue el mercado interno, pero se concentró en los segmentos de petróleo y gas, minería y construcción, y benefició sobre todo a aquellos productores de máquinas y equipos para esas industrias. Esto condujo a situaciones de estancamiento en los demás sectores y, en los casos menos competitivos, a la ampliación de las importaciones en sustitución de la oferta interna.

Los segmentos proveedores de máquinas y equipos para las industrias de extracción y prospección de petróleo, minería y construcción crecieron en forma paralela a las importaciones que complementaron la oferta nacional, configurando un comercio intraindustrial horizontal, es decir, de productos del mismo tipo y valor tecnológico similar. Cabe destacar que, a partir de 2008, esos segmentos continuaron desarrollándose y pasaron por un proceso de verticalización del comercio en favor del producto nacional. En otras palabras, el contenido tecnológico de los productos nacionales pasó a ser mayor que el de los productos importados.

Por el contrario, en los segmentos productores de máquinas y equipos para las industrias del papel y la celulosa, metalúrgica y textil, de prendas de vestir y calzado se asistió a un crecimiento superior de las importaciones. En el caso de los proveedores de la industria productora de papel y celulosa, ese crecimiento es sobre todo evidente en la oferta de productos distintos de los nacionales (comercio interindustrial), debido a la escasa diversificación de la oferta interna. En cuanto a las industrias metalúrgica y textil, el crecimiento de las importaciones en sustitución del producto nacional se debió al valor tecnológico significativamente superior de los productos extranjeros con respecto a los nacionales.

El segmento proveedor de las industrias de alimentos, bebidas y tabaco constituye un caso bastante específico, pues se caracteriza por una escasa penetración de productos importados y, al mismo tiempo, bajos coeficientes de exportación. En tal sentido, su desarrollo estuvo estrechamente ligado al aumento de la demanda en el segundo período (2006-2008), mientras que la reducción de la demanda en el período posterior a la crisis afectó directamente a su producción. Se trata, en suma, de un rubro con suficiente potencial como para absorber la demanda interna (tanto en términos tecnológicos como productivos), pero al mismo tiempo, bastante dependiente de esta. 
V

\section{Conclusión: dimensiones relevantes para la construcción de una política industrial eficaz para el sector de bienes de capital}

Al no definirse por los aspectos productivos, sino por su finalidad, la industria productora de bienes de capital es bastante heterogénea e incluye diversos segmentos con características distintas. En general, es posible distinguir dos grupos en función de su capacidad de satisfacer la demanda interna: los segmentos caracterizados por una producción nacional con potencial tecnológico para absorber la expansión del mercado interno, y aquellos que presentan una oferta interna poco diversificada y carecen de la capacidad productiva y tecnológica para hacer frente a la competencia de los productos importados.

Como se mencionó anteriormente, en el primer grupo se destacan los segmentos productores de equipos de transporte, máquinas y equipos agrícolas, equipos para la generación y distribución de energía, máquinas y equipos para la extracción y prospección de petróleo, para la minería y la construcción y, por último, para la producción de alimentos, bebidas y tabaco. Esas industrias lograron satisfacer en gran medida la demanda interna en el ciclo de expansión de las inversiones, y - en el período posterior a la crisis- crecieron sobre la base de la demanda interna. La expansión paralela de las importaciones, sobre todo entre 2005 y 2008, no obedeció a la falta de diversificación tecnológica de la estructura productiva nacional, sino a la carencia de inversiones previas (que derivó en la insuficiencia de la capacidad instalada) y a los desajustes macroeconómicos, en particular la apreciación del tipo de cambio, que fomentaron el aumento de las importaciones en detrimento de la oferta nacional.

En el segundo grupo se destacan los segmentos productores de máquinas y equipos para las industrias del papel y la celulosa, metalúrgica y textil, de prendas de vestir y calzado. En esos ramos de la industria de bienes de capital, las importaciones cubrieron más que proporcionalmente la expansión de la demanda interna, en particular debido a la carencia de potencial tecnológico de los productores. Para esas industrias, la falta de oferta nacional no es solo una cuestión de desajustes macroeconómicos o ausencia de inversión previa, de manera que esos segmentos solo podrán internalizarse mediante políticas dirigidas a los sectores demandantes y articuladas con estos.

En este segundo grupo sobresale también el segmento de informática, electrónica y comunicación, en el que la pérdida de competitividad de la industria nacional y la creciente absorción de la demanda por los productos importados debe entenderse como un caso bastante particular, pues al producir piezas, partes y componentes para otras industrias de máquinas y equipos, la reducción del costo del producto importado y su sustitución de la oferta doméstica se presentaron como una oportunidad para la expansión de los demás rubros.

En el caso de los segmentos de la industria de bienes de capital que tienen el potencial tecnológico para cubrir la expansión de la demanda, la política industrial debe concentrarse tanto en la coordinación de las inversiones (para que la demanda de máquinas no supere considerablemente la capacidad de oferta nacional), como en su dimensionamiento (para estimular la creación de oferta en los segmentos de la industria de máquinas y equipos que se demandarán posteriormente) ${ }^{24}$. A este objeto es necesario que el Estado brasileño asuma la posición de agente en el proceso de coordinación y orientación de las inversiones (ya sea directamente, como productor, o indirectamente, como inductor $)^{25}$, de

\footnotetext{
24 De acuerdo con Rodrik (2004, pág. 13), la coordinación de las inversiones y las decisiones de producción (realizada por un sector privado organizado o por iniciativa gubernamental) es un importante mecanismo de política industrial, en la medida en que la realización de inversiones por parte de una empresa A depende muchas veces de la demanda y de las inversiones de una empresa $\mathrm{B}$, y viceversa (las inversiones simultáneas hacen que todas ellas se vuelvan más lucrativas). Esta tesis no es nueva en la llamada "economía del desarrollo", pues se demostró en forma pionera en el artículo seminal de Rosenstein-Rodan (1943).

${ }^{25}$ La coordinación de las inversiones no debe necesariamente recaer en el Estado. De acuerdo con Almeida (2009), la formación de grupos nacionales estimula la formación de una cadena de proveedores nacionales, por medio de la coordinación de las inversiones y de una política industrial. Se destaca además, como señala Laplane (2004), que la orientación y la coordinación requieren también una política exterior concentrada en la estrategia de integración regional de las cadenas productivas, vista la importancia de la demanda de los países vecinos.
} 
manera que los segmentos de la industria de bienes de capital con potencial tecnológico puedan satisfacer la demanda que se ha de crear. De no haber coordinación entre la demanda y la oferta de los bienes de inversión, los segmentos que actualmente tienen potencial para satisfacer la demanda —como los de máquinas y equipos para las industrias del petróleo y gas, minería y alimentos - no lograrán aprovechar la oportunidad que se les presenta.

Además, en particular en relación con esos segmentos con potencial para satisfacer la demanda interna, es necesario que la política industrial se complemente con una política macroeconómica orientada a fomentar el desarrollo, que no contrarreste la política industrial mediante tasas de interés demasiado elevadas con respecto a los patrones internacionales y una moneda cíclicamente apreciada en términos reales. Esas condiciones limitan constantemente la eficacia de los instrumentos de financiación y aumentan la aversión al riesgo empresarial, desalentando la formación de oferta (Cano y Silva, 2010, pág. 21). Es preciso comprender que esos segmentos pueden ser competitivos, incluso en el comercio exterior, si se aprovecha la demanda interna para su expansión. Con el fin de no desperdiciar la oportunidad de crecimiento actual, se debe promover el fortalecimiento de una "competitividad auténtica", fomentando, por una parte, la absorción de la demanda interna y, por otra, la exportación, mediante la neutralidad en materia arancelaria y tipos de cambio marginalmente depreciados en términos reales, cuidando de que estos se mantengan estables a lo largo del tiempo (CEPAL, 2000, pág. 906).

Se destaca además, como señala Coutinho (2011, págs. 33 y 34), la importancia de empresas y programas líderes o "ancla" para movilizar recursos de investigación que se traduzcan en el desarrollo de tecnología en el país. De acuerdo con este autor, los ejemplos de
Petrobras (que promueve un gran avance tecnológico en la explotación del presal en aguas profundas) y de algunas empresas de agronegocios (que, con el apoyo de la Empresa Brasileña de Investigación Agropecuaria (EMBRAPA), hicieron posible el avance tecnológico en diversas empresas brasileñas) demuestran que en los sectores donde se registraron avances importantes existe por lo general una empresa líder poderosa.

Como ya se mencionó, las oportunidades que se presentan actualmente en la economía brasileña requieren una política eficaz para el sector de bienes de capital. La expansión reciente del mercado interno (en especial, sus efectos en las inversiones), la mayor capacidad del gobierno para utilizar su poder de compra y de financiamiento (con respecto al período de crisis fiscal que se vivía desde la década de 1980), la dirección de los flujos de capital extranjero (que puede redundar en inversiones directas con transferencia tecnológica), la valorización de los productos básicos (que evitaría restricciones externas, por lo menos a corto plazo) y la existencia de empresas con potencial tecnológico son algunos de los factores que se deben tener en cuenta en la consolidación de una política destinada a fomentar la competitividad del sector.

Si no se aprovecha la expansión del mercado interno como variable estratégica para la internalización de una industria tan sujeta a las oscilaciones de la demanda — como la industria de bienes de capital—y tampoco se saca partido de los factores sistémicos citados (que permitirían que esa internalización se realizara de manera organizada y selectiva), la falta de capacidad de oferta del sector de bienes de capital puede significar restricciones futuras al desarrollo de la economía, tanto en términos de la balanza de pagos como de la dependencia tecnológica. A consecuencia de ese proceso, el crecimiento económico puede restringirse nuevamente por la inversión del contexto externo. 
ANEXOS

ANEXO 1

Brasil: segmentación de la industria de bienes de capital ${ }^{a}$

\begin{tabular}{|c|c|c|}
\hline Grupos y subgrupos & CNAE $2.0^{\mathrm{b}}$ & CNAE $1.0^{\mathrm{b}}$ \\
\hline \multicolumn{3}{|c|}{ Equipos de informática, productos electrónicos, instrumentación y ópticos } \\
\hline Equipos de informática y periféricos & 262 & 302 \\
\hline Equipos de comunicación & 263 & 322 \\
\hline Aparatos y equipos de medición, prueba y control & 2651 & 332 y 333 \\
\hline Aparatos electromédicos y electroterapéuticos y equipos de radiación & 266 & 331 \\
\hline Equipos e instrumentos ópticos, fotográficos y cinematográficos & 267 & 334 \\
\hline
\end{tabular}

Equipos para generación, distribución y control de energía eléctrica

Generadores, transformadores y motores eléctricos 271

Aparatos y equipos para distribución y control de energía eléctrica

$271 \quad 311$

Tractores, máquinas y equipos para la industria agropecuaria

Tractores, máquinas y equipos para la industria agropecuaria

$283 \quad 293$

Máquinas y equipos de uso típicamente industrial

Motores, bombas, compresores y equipos de transmisión

Máquinas y equipos de uso general

2731

Máquinas herramientas

Máquinas y equipos para la prospección y extracción de petróleo

Tractores, excepto agrícolas

Máquinas y equipos para la minería y la construcción

Máquinas para la industria metalúrgica, excepto máquinas herramientas

Máquinas y equipos para las industrias de alimentos, bebidas y tabaco

Máquinas y equipos para la industria textil

Máquinas y equipos para las industrias de prendas de vestir, cuero y calzado

Máquinas y equipos para las industrias de celulosa, papel, cartón y cartonaje

Máquinas y equipos para uso industrial específico no especificados anteriormente

Fabricación de equipos de transporte

Camiones, ómnibus, cabinas, carrocerías y remolques

Embarcaciones y estructuras flotantes

Locomotoras, vagones y otros materiales rodantes

Aeronaves

$\begin{array}{cc}281 & 291 \\ 282 & 292 \text { y } 301 \\ 284 & 294 \\ 2851 & 2951 \\ 2853 & 2953 \\ 2852 \text { y } 2854 & 2952 \text { y } 2954 \\ 2861 & 2961 \\ 2862 & 2962 \\ 2863 & 2963 \\ 2864 & 2964 \\ 2865 & 2965 \\ 2866 \text { y } 2869 & 2969\end{array}$

Fuente: Elaboración propia sobre la base de datos de la Comisión Nacional de Clasificación (CONCLA)-Instituto Brasileño de Geografía y Estadística (IBGE).

a La compatibilización de las versiones 1.0 y 2.0 de la Clasificación Nacional de Actividades Económicas (CNAE) se realizó sobre la base de los datos de la Comisión Nacional de Clasificación del IBGE con el propósito de extender la comparación a todo el período de análisis. La compatibilización de las dos clasificaciones es necesaria, pues se utilizan datos de la Encuesta Industrial Anual-Empresa y de la Encuesta Industrial Anual-Producto, ambas del IBGE, que fueron publicadas en momentos distintos; la primera entre 1996 y 2007 , en el marco de la CNAE 1.0, y la segunda entre 2007 y 2012, en el marco de la CNAE 2.0. Para el análisis también se utilizaron datos de la Fundación Centro de Estudios de Comercio Exterior (FUNCEX) sobre comercio exterior y de AliceWeb, del Ministerio para el Desarrollo, la Industria y el Comercio Exterior (MDIC). En este caso, la compatibilización se basó en la Nomenclatura Común del MERCosur (NCM), que es la clasificación utilizada por el MDIC para suministrar los datos de comercio.

b Las versiones 1.0 y 2.0 de la CNAE no necesariamente presentarán los mismos resultados, pues algunos de los productos de una clasificación no figuran dentro del grupo compatible de la otra. 
Brasil: Otros indicadores de comercio de los segmentos productores de máquinas y equipos para uso industrial

A. Relación entre el valor unitario de las exportaciones y las importaciones

\begin{tabular}{lcccccccccc}
\hline & 2000 & 2001 & 2002 & 2003 & 2004 & 2005 & 2006 & 2007 & 2008 & 2009 \\
\hline Extracción y prospección de petróleo & 0,54 & 0,52 & 0,58 & 0,60 & 0,43 & 0,50 & 0,60 & 0,64 & 1,03 & 1,34 \\
Minería y construcción & 0,79 & 0,96 & 0,97 & 0,77 & 0,90 & 0,90 & 0,84 & 0,99 & 1,12 & 1,00 \\
Metalurgia, excepto máquinas herramientas & 0,21 & 0,18 & 0,25 & 0,28 & 0,36 & 0,29 & 0,41 & 0,44 & 0,41 & 0,44 \\
Alimentos, bebidas y tabaco & 0,29 & 0,19 & 0,27 & 0,30 & 0,24 & 0,35 & 0,32 & 0,43 & 0,29 & 0,31 \\
Textil, prendas de vestir y calzado & 0,60 & 0,58 & 0,57 & 0,62 & 0,62 & 0,72 & 0,75 & 0,81 & 0,96 & 0,83 \\
Papel y celulosa & 0,69 & 0,78 & 0,60 & 0,63 & 0,54 & 0,60 & 0,82 & 0,81 & 0,91 & 0,64 \\
\hline
\end{tabular}

Fuente: Elaboración propia sobre la base de datos de AliceWeb del Ministerio para el Desarrollo, la Industria y el Comercio Exterior (MDIC).

B. Índice de Grubel y Lloyd

\begin{tabular}{|c|c|c|c|c|c|c|c|c|c|c|}
\hline & 2000 & 2001 & 2002 & 2003 & 2004 & 2005 & 2006 & 2007 & 2008 & 2009 \\
\hline Extracción y prospección de petróleo & 0,37 & 0,36 & 0,52 & 0,54 & 0,55 & 0,62 & 0,65 & 0,57 & 0,56 & 0,42 \\
\hline Minería y construcción & 0,36 & 0,31 & 0,33 & 0,28 & 0,20 & 0,25 & 0,29 & 0,38 & 0,39 & 0,40 \\
\hline Metalurgia, excepto máquinas herramientas & 0,39 & 0,21 & 0,32 & 0,32 & 0,38 & 0,35 & 0,35 & 0,32 & 0,28 & 0,28 \\
\hline Alimentos, bebidas y tabaco & 0,37 & 0,46 & 0,56 & 0,56 & 0,52 & 0,49 & 0,40 & 0,55 & 0,45 & 0,43 \\
\hline Textil, prendas de vestir y calzado & 0,09 & 0,10 & 0,13 & 0,15 & 0,16 & 0,21 & 0,15 & 0,16 & 0,18 & 0,16 \\
\hline Papel y celulosa & 0,31 & 0,25 & 0,38 & 0,39 & 0,51 & 0,37 & 0,48 & 0,29 & 0,51 & 0,26 \\
\hline
\end{tabular}

Fuente: Elaboración propia sobre la base de datos de AliceWeb del Ministerio para el Desarrollo, la Industria y el Comercio Exterior.

ANEXO 3

Brasil: síntesis de los resultados de la industria de máquinas y equipos industriales

Destino $\quad 1^{\mathrm{er}}$ período $(2002-2004) \quad 2^{\mathrm{o}}$ período $(2005-2008) \quad 3$ período $(2008-2012)$

Extracción y Estancamiento en el Crecimiento basado en el mercado interno, prospección mercado interno y bajo de petróleo coeficiente de exportación pero en paralelo a las importaciones (comercio intraindustrial horizontal)

Minería y Crecimiento basado en las Crecimiento basado en las exportaciones y construcción exportaciones el mercado interno, pero con un aumento superior de las importaciones (comercio intraindustrial horizontal)

\begin{tabular}{|c|c|c|c|}
\hline $\begin{array}{l}\text { Alimentos, } \\
\text { bebidas y } \\
\text { tabaco }\end{array}$ & $\begin{array}{l}\text { Estancamiento en el } \\
\text { mercado interno y bajo } \\
\text { coeficiente de exportación }\end{array}$ & $\begin{array}{l}\text { Crecimiento basado en el mercado interno, } \\
\text { pero en paralelo a las importaciones } \\
\text { (comercio intraindustrial horizontal) }\end{array}$ & $\begin{array}{l}\text { Estancamiento debido a la reducción de } \\
\text { las inversiones y la dificultad de acceso al } \\
\text { mercado externo }\end{array}$ \\
\hline $\begin{array}{l}\text { Papel y } \\
\text { celulosa }\end{array}$ & $\begin{array}{l}\text { Escaso crecimiento a pesar } \\
\text { del alto coeficiente de } \\
\text { exportación }\end{array}$ & $\begin{array}{l}\text { Crecimiento basado en el mercado interno } \\
\text { en } 2007 \text {, pero con un aumento superior de } \\
\text { las importaciones (comercio interindustrial: } \\
\text { escasa diversificación de la oferta nacional) }\end{array}$ & $\begin{array}{l}\text { Estancamiento debido a la reducción de las } \\
\text { inversiones y a la escasa diversificación, } \\
\text { que favoreció la penetración de productos } \\
\text { de importados }\end{array}$ \\
\hline $\begin{array}{l}\text { Metalurgia, } \\
\text { excepto } \\
\text { máquinas } \\
\text { herramientas }\end{array}$ & $\begin{array}{l}\text { Escaso crecimiento basado } \\
\text { casi exclusivamente en las } \\
\text { exportaciones }\end{array}$ & $\begin{array}{l}\text { Crecimiento basado en el mercado interno, } \\
\text { pero con un aumento superior de las } \\
\text { importaciones, especialmente de valor } \\
\text { tecnológico superior (comercio vertical) }\end{array}$ & $\begin{array}{l}\text { Retroceso debido a la reducción de las } \\
\text { inversiones y al aumento de la penetración } \\
\text { de productos importados de mayor } \\
\text { contenido tecnológico }\end{array}$ \\
\hline $\begin{array}{l}\text { Textil, } \\
\text { prendas } \\
\text { de vestir y } \\
\text { calzado }\end{array}$ & $\begin{array}{l}\text { Estancamiento y aumento } \\
\text { del coeficiente de } \\
\text { exportación }\end{array}$ & $\begin{array}{l}\text { Escaso crecimiento, pues el mercado } \\
\text { interno fue absorbido casi completamente } \\
\text { por las importaciones (comercio inter- } \\
\text { industrial: escasa diversificación de la } \\
\text { oferta interna) }\end{array}$ & $\begin{array}{l}\text { Retroceso debido a la reducción de las } \\
\text { inversiones y al aumento de la penetración } \\
\text { de productos importados de mayor } \\
\text { contenido tecnológico }\end{array}$ \\
\hline
\end{tabular}

Fuente: Elaboración propia.
Estancamiento debido a la reducción de as inversiones y la dificultad de acceso al externo

Estancamiento debido a la reducción de las que favoreció la penetración de productos de importados de productos importados de mayor contenido tecnológico
Crecimiento basado en el mercado interno, con intensificación del contenido tecnológico

Crecimiento basado en las exportaciones y en el mercado interno, con intensificación del contenido tecnológico 


\section{Bibliografía}

Alem, A.C. y R.M. Pessoa (2005), "O setor de bens de capital e o desenvolvimento econômico: quais são os desafios?", BNDES Setorial, $\mathrm{N}^{\circ}$ 22, Río de Janeiro, Banco de Desarrollo del Brasil.

Almeida, M. (2009), "Desafios da real política industrial brasileira do século XxI", Texto para Discussão, $\mathrm{N}^{\circ} 1452$, Instituto de Investigación Económica Aplicada (IPEA), diciembre.

Amsden, A.H. (2001), Asia's Next Giant: South Korea and the Late Industrialization, Nueva York, Oxford University Press.

Baltar, C.T. (2007), "Padrão do comércio brasileiro no período 2003-2005: um estudo do conteúdo dos fluxos de importação e exportação", Campinas, Instituto de Economía/Universidad Estadual de Campinas.

Bielschowsky, R. (1999), "Investimentos na indústria brasileira depois da abertura e do real: mini-ciclo de modernizações. 1995-97", serie Reformas Económicas, $\mathrm{N}^{\circ} 44$ (LC/L.1289), Santiago, Comisión Económica para América Latina y el Caribe (CEPAL).

Cano, W. y A.L.G. Silva (2010), "Política industrial no governo Lula", Texto para Discussão, $\mathrm{N}^{\circ} 181$, Campinas, Instituto de Economía/Universidad Estadual de Campinas.

CEPAL (Comisión Económica para América Latina y el Caribe) (2000), "Estudo econômico da América Latina, 1949", Cinqüenta anos de pensamento na CEPAL, R. Bielschowsky (org.), vol. 1, Río de Janeiro, Editora Record.

(2000), "Política de ajuste e renegociação da dívida externa na América Latina", Cinqüenta anos de pensamento na CEPAL, R. Bielschowsky (org.), vol. 2, Río de Janeiro, Editora Record.

Coutinho, L. (2011), "O Brasil do século XXI: desafios do futuro", $O$ Brasil do século XXI, A. Delfim Netto (coord.), São Paulo, Saraiva.

Erber, P.S. (coord.) (1974), "Absorção e criação de tecnologia na indústria de bens de capital", FINEP Séries Pesquisas, $\mathrm{N}^{\circ} 2$, Río de Janeiro, Arte Moderna.

Feltrin, L. (2005), "Mudanças estruturais na inserção brasileira no comércio internacional de bens de capital: 1991-2000", Perspectiva Econômica, vol. 1, $\mathrm{N}^{\circ} 2$.
Gouvea, R.R. y G.T. Lima (2013), "Balance-of-paymentsconstrained growth in a multisectoral framework: a panel data investigation", Journal of Economic Studies, vol. 40, $\mathrm{N}^{\circ} 2$, Emerald Group Publishing.

Laplane, M. (2004), "A política industrial em perspectiva", Econômica, vol. 5, $\mathrm{N}^{\circ}$ 2, Río de Janeiro.

Lundvall, B.-A. (1988), "Innovation as an interactive process: from user-producer interaction to the national system of innovation", Technical Change and Economic Theory, G. Dosi y otros (ed.), Londres, Pinter Publishers.

Nassif, A. (2008), "Estructura y competitividad de la industria brasileña de bienes de capital", Revista de la CEPAL, $\mathrm{N}^{\circ} 96$ (LC/G.2396-P), Santiago, Comisión Económica para América Latina y el Caribe (CEPAL).

Resende, M.F.C. y P. Anderson (1999), "Mudanças estruturais na indústria brasileira de bens de capital", Texto para Discussão IPEA, $\mathrm{N}^{\circ}$ 658, Brasilia [en línea] http://www.ipea.gov.br/ agencia/images/stories/PDFs/TDs/td_0658.pdf.

Rodrik, D. (2004), "Industrial policy for the twenty-first century", Faculty Research Working Paper Series, N RWP04-047, Universidad de Harvard [en línea] https://research.hks.harvard. edu/publications/getFile.aspx? $\mathrm{Id}=146$.

Rosenstein-Rodan, P.N. (1943), "Problems of industrialisation of Eastern and South-Eastern Europe", The Economic Journal, vol. $53, \mathrm{~N}^{\circ} 2$.

Serrano, F. y R. Summa (2011), "Política macroeconômica, crescimento e distribuição de renda na economia brasileira dos anos 2000", Observatório da Economia Global, № 6 , Campinas, Universidad Estadual de Campinas.

Vermulm, R. y F. Erber (2002), Estudo da competitividade das cadeias integradas no Brasil: impactos das zonas de livre comércio. Cadeia: bens de capital - Nota Técnica Final, Campinas, Instituto de Economía/Universidad Estadual de Campinas. 